\title{
Quatro Décadas de Mobilidade Social no Brasil ${ }^{*}$
}

\section{Carlos Antonio Costa Ribeiro}

Professor e pesquisador do Instituto de Estudos Sociais e Políticos (IESP), da Universidade do Estado do Rio de Janeiro (UERJ). E-mail: carloscr@iesp.uerj.br

\section{INTRODUÇÃO}

\begin{abstract}
A o estabelecer o padrão e a força da associação entre a classe de origem, definida pela ocupação do pai quando o filho estava crescendo, e a classe de destino, definida pela ocupação do filho adulto, as análises sobre mobilidade social possibilitam o estudo sintético da desigualdade de oportunidades de ascensão social. No Brasil há informações sobre os padrões e tendências da mobilidade social para as décadas de 1970, 1980 e 1990 (dados das Pesquisas Nacionais por Amostragem Domiciliar - PNADs de 1973, 1982, 1988 e 1996). Os dados brasileiros são de alta qualidade e foram analisados em diversos estudos tratando de vários aspectos relevantes não só da mobilidade de classes ou ocupacional, medida pelo percentual total (taxas absolutas) de filhos adultos em posições de classe de destino diferentes de sua classe de origem (de seus pais), como também do grau, dos padrões e das mudanças na desigualdade de oportunidades ou na fluidez social (termos sinônimos), medida pelas chances relativas de pessoas com classes de origem diferente alcançarem classes de destino iguais (Silva, 1979;
\end{abstract}

\footnotetext{
* Agradeço aos dois pareceristas pelos comentários. As sugestões e críticas foram extremamente úteis para melhorar o texto, a apresentação dos conceitos e algumas análises. A responsabilidade pelo resultado final é, obviamente, de minha inteira responsabilidade. Este artigo usa dados coletados durante o projeto “Dimensões Sociais das Desigualdades" coordenado por Nelson do Valle Silva e financiado pelo Conselho Nacional de Desenvolvimento Científico e Tecnológico (CNPq)/Instituto do Milênio.
}

DADOS - Revista de Ciências Sociais, Rio de Janeiro, vol. 55, n-3, 2012, pp. 641 a 679. 
Pastore, 1981; Silva e Roditi, 1986; Scalon, 1999; Silva, 1999; Pastore e Silva, 2000; Ribeiro e Scalon, 2001; Ribeiro, 2006; Ribeiro, 2007). O objetivo deste artigo é apresentar análises para a primeira década do século XXI, ou seja, apresentar análises usando os dados mais recentes coletados no final de 2008. Assim, o artigo pretende completar uma série histórica de quatro décadas (1970, 1980, 1990 e 2000).

O que ocorreu com a mobilidade social e a desigualdade de oportunidades entre 1996 e 2008 é extremamente relevante, tendo em vista que o país passou por mudanças significativas neste período. Em particular, entre meados da década de 1990 e o fim da década de 2010 houve uma diminuição significativa da desigualdade de renda ${ }^{1}$. Vários fatores contribuíram para esta diminuição, entre os quais se pode citar o aumento da escolaridade da população, as políticas de transferência de renda, e a diminuição dos retornos educacionais (Ferreira et alii, 2006). Um estudo anterior (Torche e Ribeiro, 2010) mostra que, assim como ocorre com a diminuição da desigualdade de renda, há uma tendência de diminuição na desigualdade de oportunidades de mobilidade social que, entre 1988 e 1996, parece estar mais fortemente relacionada à diminuição da associação entre educação alcançada e classe de destino. Em outras palavras, a diminuição observada na desigualdade de oportunidades também parece estar relacionada à diminuição dos retornos educacionais. Em outros países europeus, França e Suécia, o principal mecanismo parece ser o de equalização educacional ou diminuição das desigualdades de oportunidades educacionais (Breen, 2004; Breen e Jonsson, 2007), enquanto nos Estados Unidos o mecanismo de composição relacionado à expansão universitária parece ter sido o mais importante (Hout, 1988). Tendo em vista que no Brasil houve uma enorme expansão educacional nas duas últimas décadas, estes mecanismos observados em outros países podem ter se tornado mais relevantes desde meados da década de 1990. De fato, nas últimas duas décadas houve quatro mandatos presidenciais que, de certa forma, contribuíram efetivamente para avançar políticas de estabilização monetária, crescimento econômico, expansão do sistema educacional e proteção social. Portanto, verificar o que ocorreu com a mobilidade social e a desigualdade de oportunidades neste período é altamente relevante.

Como mencionamos, estudos anteriores indicam que o mecanismo de diminuição dos retornos educacionais está relacionado às tendências das desigualdades de renda e de oportunidades de mobilidade social 
(Torche e Ribeiro, 2010; Ferreira et alii, 2006). No caso da desigualdade de renda, se outros aspectos não se modificam, um aumento do acesso a níveis educacionais mais elevados faz com que aumente a oferta de mão de obra qualificada. Consequentemente, os retornos em renda para esta mão de obra tendem a diminuir levando, assim, a uma diminuição da desigualdade de renda porque a diferença salarial entre os que têm educação mais elevada e os que têm menos escolaridade diminui. No caso da mensuração da desigualdade de oportunidades de mobilidade social, medida pela associação entre classe de origem e de destino, é possível fazer uma decomposição em quatro fatores envolvendo classe de origem (que denominaremos de O), classe de destino (que denominaremos de D) e educação alcançada (que denominaremos de E).

Os caminhos ou fatores que determinam a ligação entre origem e destino de classe são: (1) a associação entre origem de classe $(O)$ e educação alcançada pelos filhos (E) - caso esta associação (OE, entre origem e educação) diminua podemos dizer que diminuiu a desigualdade de oportunidades educacionais (mecanismo de equalização educacional); (2) a associação entre educação (E) e classe de destino (D) - caso esta associação (ED, entre educação e destino de classe) diminua podemos dizer que houve uma diminuição nas vantagens geradas por diplomas educacionais (mecanismo de diminuição dos retornos educacionais); (3) a associação entre origem $(\mathrm{O})$ e destino de classes $(\mathrm{D})$ nos diferentes níveis educacionais (E) - caso haja aumento percentual de pessoas com diplomas de ensino médio e superior e a associação entre origem e destino de classe seja mais fraca nestes níveis educacionais (ODE, associação entre origem e destino em cada nível educacional) pode haver uma diminuição da desigualdade de oportunidades (mecanismo de composição); e (4) a associação direta, controlando por educação, entre classe de origem (O) e de destino (D) - caso esta associação (OD I E, associação entre origem e destino descontando o efeito de educação) diminua podemos dizer que as vantagens e desvantagens passadas diretamente de pais para filhos diminuíram (mecanismo de aumento da fluidez líquida). Ao observar a associação entre origem e destino de classe sem controlar estatisticamente pela educação alcançada pelos filhos, não sabemos qual dos quatro componentes, ou mecanismos, é mais relevante. Ao passo que, ao fazermos a decomposição dos quatro efeitos, podemos verificar qual deles mais contribui para as tendências de diminuição da desigualdade de oportunidades. Sendo assim, ao estudar as desigualdades, seja de renda ou de oportunidades, é importante ir além 
da simples mensuração de suas tendências históricas e níveis (tamanho da desigualdade) para uma melhor especificação de suas características e aspectos. No caso deste artigo, pretendemos verificar em que medida cada um dos quatro mecanismos descritos acima explica as tendências, já conhecidas, de diminuição da desigualdade de oportunidades desde a década de 1970, e em particular de 1996 a 2008, período para o qual ainda não há análises realizadas. Sabemos que entre 1973 e 1996 o mecanismo de diminuição dos retornos educacionais desempenhou papel importante, mas não sabemos o que ocorreu desde então. A retomada do crescimento econômico, a diminuição da desigualdade de renda e a expansão do nível educacional da população foram importantes mudanças desde 1996 que podem ter tido impactos nos mecanismos descritos acima.

Neste artigo apresentamos análises tanto para homens quanto para mulheres. Por muitas décadas as análises sobre mobilidade de classe se concentraram na análise dos dados para homens. Para justificar essa estratégia os estudiosos lançavam mão do argumento de que os homens tinham participação mais constante no mercado de trabalho do que as mulheres e que, portanto, a definição de classe social das famílias poderia ser dada apenas pela posição dos homens (Goldthorpe, 1983). Hoje em dia este tipo de abordagem parece não fazer mais sentido dado o enorme aumento da participação feminina no mercado de trabalho. Neste sentido, apresentamos as tendências e os padrões de mobilidade e de fluidez social tanto para homens quanto para mulheres.

O artigo está dividido em sete partes, incluindo a Introdução. A segunda descreve o contexto de mudanças sociais e econômicas no período estudado. A terceira seção apresenta os dados, as variáveis, os principais conceitos e os modelos estatísticos usados para estimar as tendências da fluidez social (desigualdade de oportunidades). A quarta seção discute brevemente as taxas absolutas de mobilidade social e as tendências de expansão do nível educacional da população entre 1973 e 2008. A quinta se dedica à discussão das análises e resultados sobre as tendências da desigualdade de oportunidades (fluidez social) para homens e mulheres entre 1973 e 2008. A sexta parte apresenta simulações que permitem determinar qual dos quatro mecanismos descritos acima caracteriza melhor as tendências da fluidez social. No final são resumidas as principais conclusões e suas implicações. 


\section{MOBILIDADE SOCIAL NO BRASIL MODERNO}

Do início da década de 1970 ao final dos anos 2000 o Brasil passou por diversas transformações importantes que afetaram a dinâmica das desigualdades de oportunidades de mobilidade social. Na realidade já há alguns estudos que avaliam o que ocorreu até 1996, data da última pesquisa do Instituto Brasileiro de Geografia e Estatística (IBGE) com dados sobre mobilidade social (Pastore e Silva, 2000; Ribeiro, 2007; Torche e Ribeiro, 2010). O objetivo deste artigo é completar esta série histórica até o final da última década. De qualquer forma, vale a pena descrever brevemente os desenvolvimentos econômicos e sociais que ocorreram desde o início do período, desde a década de 1970, e que tiveram impactos importantes nas tendências da mobilidade social e da desigualdade de oportunidades (fluidez social).

Sabemos que entre 1973 e 1982, anos das duas primeiras pesquisas (PNADs) analisadas neste artigo, o Brasil ainda experimentava as consequências de um período de acelerado crescimento econômico, que veio acompanhado de um aumento sem precedentes da urbanização. Este período é, portanto, caracterizado por fortes mudanças na estrutura de classes brasileira que afetaram enormemente a dinâmica da desigualdade de oportunidades e da mobilidade social. De fato, Ribeiro (2007) mostrou que uma enorme diminuição da desigualdade de oportunidades ocorreu neste período, bem como grandes fluxos de mobilidade das classes sociais rurais para as urbanas. Fora a Coreia do Sul, nenhum outro país se caracterizou por tanta mobilidade social das classes rurais para as urbanas como o Brasil na década de 1970 (Ribeiro, 2007). A desigualdade de oportunidades também diminuiu significativamente, embora tenha permanecido maior no Brasil do que em outros países (Ishida, 2005; Breen e Jonsson, 2007).

Este período de crescimento foi seguido por duas décadas de estagnação econômica. De 1982 até o final dos anos 1990 a economia brasileira praticamente não cresceu e os níveis de desigualdade de renda continuaram extremamente elevados. A desigualdade de oportunidades, no entanto, permaneceu diminuindo como indicado em diversos estudos (Ribeiro, 2007; Torche e Ribeiro, 2010), embora a diminuição tenha sido maior entre 1973 e 1982 (Ribeiro, 2007). A década de 1980 também se caracterizou por uma grande expansão do mercado de trabalho, que passou a contar crescentemente com a participação feminina (Hasenbalg, 1988; Hasenbalg e Silva, 2003). Embora a crise tenha sido forte e 
os níveis de inflação tenham sido os mais elevados de toda a história do país, foi durante a década de 1980 que se iniciou um processo tardio de expansão do acesso ao sistema educacional. A partir de 1982, quando diversos governos de oposição foram eleitos nas primeiras eleições diretas para governador depois de um longo período de ditadura militar, se iniciou uma forte expansão dos sistemas educacionais de nível primário (fundamental) e secundário (médio) (Franco et alii, 2007)².

As tendências da desigualdade de oportunidades (fluidez social) durante este período já foram amplamente analisadas, mas o que ocorreu desde 1996 será analisado pela primeira vez neste artigo. O período mais recente se caracterizou por mudanças consideráveis no plano econômico e social do país. Quatro mandatos presidenciais foram concluídos, dois de Fernando Henrique Cardoso e mais dois de Luiz Inácio Lula da Silva. Embora analistas deste período tendam a dividir os dois mandatos e avaliar as diferenças entre ambos os governos, no caso da mobilidade social intergeracional e da desigualdade de oportunidades é mais relevante analisar o período todo em conjunto. Ou seja, não é pertinente fazer uma diferença fina do impacto de cada um dos governos sobre as tendências da mobilidade e da desigualdade de oportunidades. Em conjunto os quatro mandatos avançaram em importantes fatores que podem ser correlacionados às tendências que descrevemos e analisamos neste artigo.

Em 1994 a inflação, que na década de 1980 ficou completamente fora de controle, foi finalmente vencida, o que contribuiu bastante para a diminuição da pobreza e da desigualdade de renda no país (Ferreira et alii, 2006). Também foi a partir da década de 1990 que houve uma expansão realmente significativa do sistema educacional brasileiro. Foi só na primeira metade da década de 1990 que o acesso das crianças e jovens ao ensino fundamental e médio chegou perto da universalização. Além disso, a desigualdade de renda diminuiu lentamente até o início da década de 2000, quando começou a declinar de forma bastante mais significativa. A década de 2000 também pode ser vista como aquela em que o crescimento econômico foi retomado no país. Todos estes fatores podem ter influenciado as tendências da desigualdade de oportunidades entre 1996 e 2008 (anos das duas últimas pesquisas analisadas neste estudo). É importante ressaltar que neste artigo estamos tratando da mobilidade intergeracional, entre a geração dos pais e a dos filhos, e principalmente da desigualdade de oportunidades, mensurada pela associação estatística entre classes de origem (dos pais) e de destino 
(dos filhos). Estes fenômenos populacionais tendem a mudar de forma mais lenta do que outros fenômenos sociais, o que significa que as tendências observadas anteriormente devem ter continuado seguindo o mesmo caminho que já foi descrito em trabalhos anteriores analisando os dados das décadas de 1970, 1980 e 1990 (Pastore e Silva, 2000; Ribeiro, 2007; Torche e Ribeiro, 2010). Também podemos pensar de forma inversa, ou seja, pensar que mesmo pequenas mudanças entre 1996 e 2008 podem ser interpretadas como altamente relevantes.

\section{DADOS, VARIÁVEIS, CONCEITOS E MÉTODOS}

\section{Dados}

Neste artigo usamos dados das PNAD-IBGE de 1973, 1982, 1988 e 1996. Todas essas pesquisas incluem informações sobre mobilidade social, ou seja, informações sobre a ocupação do pai dos respondentes quando estes estavam crescendo. Além das PNADs, usamos a Pesquisa Dimensões Sociais das Desigualdades (PDSD daqui em diante) de 2008. Em conjunto estas pesquisas permitem estudar quatro décadas de mobilidade social no Brasil. Tanto a PNAD quanto a PDSD são amostras representativas da população brasileira urbana e rural, com exceção da área rural das regiões Norte e Centro-Oeste, que foram excluídas das pesquisas posteriores a 1973 para garantir comparabilidade. As amostras construídas incluem apenas homens e mulheres que estavam no mercado de trabalho no momento da pesquisa e para os quais havia informação para ocupação de seus pais. Nas PNADs as amostras de homens e mulheres entre 30 e 64 anos de idade são respectivamente de 32.333 homens e 8.852 mulheres em 1973; 52.615 homens e 16.719 mulheres em 1982; 58.500 homens e 15.043 mulheres em 1988; e 68.760 homens e 16.824 mulheres em 1996. Na PDSD todos os chefes e cônjuges foram entrevistados, mas usamos aqui apenas os dados para pessoas entre 30 e 64 anos de idade que estavam no mercado de trabalho e com informação relevante para ocupação dos pais e dos respondentes o que resulta em uma subamostra de 2.713 homens e 2.189 mulheres. As amostras das PNADs e da PDSD são inteiramente probabilísticas e estratificadas em múltiplos estágios, o que permite inferências acuradas dos parâmetros populacionais. As amostragens seguem um procedimento probabilístico em três etapas. Na primeira foram selecionados os municípios, na segunda os setores censitários dentro dos municípios, e na terceira os domicílios dentro dos setores ${ }^{3}$. 


\section{Variáveis e Conceitos Básicos}

A desigualdade de oportunidades é mensurada pela correlação ou associação entre classe de origem, definida pela ocupação dos pais dos respondentes quando estes estavam crescendo, e classe de destino, mensurada pela ocupação dos respondentes na semana e/ou ano da pesquisa. Neste artigo, usamos o esquema de classes CASMIN ${ }^{4}$ com seis categorias: Profissionais e administradores (I+II), Trabalhadores não manuais de rotina (IIIab), Pequenos proprietários com e sem empregados (IVab), Trabalhadores rurais e pequenos fazendeiros $(\mathrm{IV} c+\mathrm{VIIb})$, Trabalhadores manuais qualificados (V+VI), e Trabalhadores manuais não qualificados (VIIa). Este esquema de classes segue a ideia de que as posições na estrutura de classes são determinadas por diferentes relações de emprego e mercado (Goldthorpe e Erickson, 1993). As diferentes classes se caracterizariam por níveis altos ou baixos de especificidade nos ativos de capital humano que os indivíduos naquelas posições comandam, e pela dificuldade de monitorar o trabalho destes indivíduos (Goldthorpe, 2000). Os profissionais e administradores (I+II) têm alto nível de capital humano e exercem atividade de difícil monitoramento, ou seja, têm muita liberdade para executar seu trabalho. A classe de trabalhadores não manuais (IIIab), principalmente burocratas e pessoal de escritório e vendas, conta com indivíduos com baixo capital humano e cujo trabalho é passível de algum monitoramento. A classe de pequenos proprietários (IVab) é composta por pessoas que trabalham por conta própria e, portanto, têm uma situação de emprego muito diversa da dos outros empregados. As classes de trabalhadores rurais (IVc+VIIb), trabalhadores manuais não qualificados urbanos (VIIa) e trabalhadores qualificados (V+VI) são compostas por indivíduos com pouco capital humano e cujos trabalhos são monitorados rigidamente. São as classes trabalhadoras tradicionais.

Um esquema com apenas seis classes é, obviamente, altamente agregado, ou seja, há muita variação dentro de cada classe. Certamente, seria melhor usar um esquema com mais categorias, mas, para nossos propósitos comparativos que levam em conta diversas dimensões (educação, origem, destino, período e sexo) e mudanças ao longo do tempo, as tabelas não podem ser muito desagregadas ${ }^{5}$. Além disso, a comparação com os dados para 2008 só pode ser feita quando diminuímos o número de categorias de classe para seis, ou seja, há limitação nos dados que nos leva a perder poder explicativo. No entanto, as tendências observadas não mudam quando usamos mais categorias para a análise 
dos quatro primeiros anos ${ }^{6}$. Nosso principal objetivo neste artigo é estimar as tendências temporais e não explicar em detalhes os padrões de associação entre classes de origem e de destino.

Classes de origem e destino são combinadas em tabelas de mobilidade social (6 por 6) para cada ano $(1973,1982,1988,1996$, e 2008). Estas tabelas são usadas para estimar as tendências históricas na associação entre origem e destino, o que também é conhecido como grau de fluidez social ou de desigualdade de oportunidades. Além disso, as tabelas são usadas para mensurar as taxas absolutas de mobilidade social, ou seja, o percentual de pessoas que se encontram em posições de classe diferentes de seus pais ou que mudaram de uma classe de origem específica para alguma outra classe de destino, ou então que permaneceram na mesma classe de seus pais.

Aqui cabe uma pequena digressão para explicar a diferença entre os conceitos de mobilidade social e de desigualdade de oportunidades. $\mathrm{O}$ primeiro conceito é normalmente usado para se referir aos percentuais totais de mobilidade social entre classes de origem e de destino. Na literatura sobre mobilidade e estratificação social estes percentuais já foram denominados de taxas absolutas de mobilidade social, mobilidade estrutural ou simplesmente mobilidade social. Todos os termos se referem a cálculos percentuais usando as tabelas ou matrizes cruzando classes de origem por classes de destino. O segundo termo, desigualdade de oportunidades (de mobilidade social), também já foi denominado por diferentes termos, tais como taxas relativas de mobilidade social, fluidez social, mobilidade de circulação ou desigualdade de oportunidades. Atualmente esta ideia é definida pela associação estatística entre classes de origem e de destino. Na literatura sociológica essa associação é mensurada a partir das razões de chances estimadas por modelos log-lineares. De forma simples, podemos dizer que essas razões de chance comparam as chances de pessoas com origens em classes sociais distintas (alta e baixa, por exemplo) alcançarem as mesmas classes sociais de destino (alta, por exemplo) ao invés de outra classe (baixa, por exemplo). Se estas chances relativas, ou vantagens relativas, diminuem ao longo do tempo dizemos que houve diminuição na desigualdade de oportunidades, caso aumentem dizemos que houve aumento deste tipo de desigualdade, e caso não mudem dizemos que não houve mudança nas desigualdades. Portanto, para mensurar a desigualdade de oportunidades é necessário estimar modelos estatísticos, que, no caso de dados categóricos como os usados neste artigo, são 
os modelos log-lineares (apresentaremos a seguir os modelos usados neste artigo).

Além das variáveis para classes de origem e de destino para período (1973, 1982, 1988, 1996 e 2008) também usamos outra para qualificação educacional. Como estamos analisando dados para pessoas que tinham entre 30 e 64 anos em cada um dos anos das pesquisas utilizadas, temos que levar em conta a época em que estas pessoas passaram pelo sistema educacional. As pessoas mais velhas de nossas amostras tinham 64 anos em 1973 e, portanto, podem ter entrado na escola com seis anos de idade, ou seja, em 1915. Já as pessoas mais jovens de nossas amostras, com 30 anos em 2008, podem ter entrado na escola com seis anos, em 1984 e completado a universidade com 25 anos em 2003. Em outras palavras, estamos tratando de um longuíssimo período de mudanças no sistema educacional, o que torna necessário encontrar uma classificação de etapas do sistema educacional que seja válida para a comparação ao longo de todo o período. Por exemplo, até 1971 a escolaridade era obrigatória apenas para as quatro primeiras séries (que eram denominadas de educação elementar). A partir desta data o primário, incluindo oito séries, passou a ser obrigatório por lei para todas as crianças. Para possibilitar a comparação mensuramos a educação da seguinte forma: 0 a 3 anos de escolaridade (equivalente ao antigo elementar incompleto); 4 anos de escolaridade (equivalente ao antigo elementar completo, ou metade do primário); 5 a 7 anos de escolaridade (equivalente ao antigo primário incompleto); 8 a 10 anos de escolaridade (equivalente ao antigo primário completo); 11 anos de escolaridade (equivalente ao antigo secundário completo); e alguma educação superior ou 12 anos ou mais de escolaridade. As análises são feitas separadamente para homens e mulheres que se encontravam no mercado de trabalho, ou seja, não fazemos nenhuma comparação direta (usando o mesmo modelo estatístico) entre homens e mulheres. O principal objetivo é analisar as tendências históricas, ao longo do período que vai de 1973 a 2008, da desigualdade de oportunidades (fluidez social) para homens e mulheres.

As variáveis para classes de origem $(\mathrm{O})$, classes de destino (D) e educação alcançada (E) são organizadas em diferentes tabelas (comparadas ao longo dos cinco anos separadamente para homens e mulheres) com o objetivo de analisar o impacto de quatro mecanismos que podem ter influenciado as tendências da desigualdade de oportunidades (ou fluidez social) entre 1973 e 2008. O principal objetivo é verificar qual, ou quais, destes quatro mecanismos explica a diminuição da desigualda- 
Figura 1

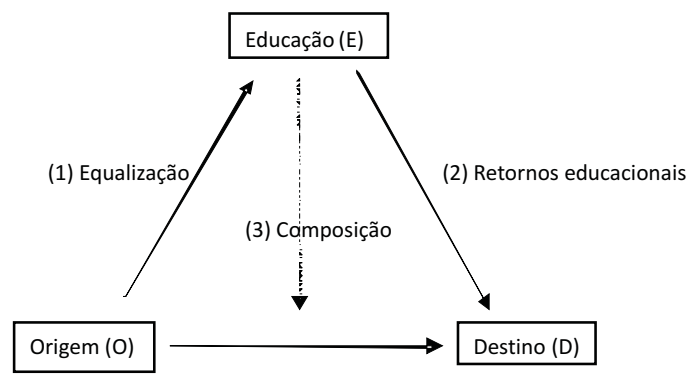

(4) Fluidez líquida

Elaboração do autor.

de de oportunidades observada entre 1973 e 2008. Os quatro mecanismos, que foram descritos acima, podem ser observados na Figura 1, que esquematiza o triângulo básico dos estudos de estratificação e mobilidade social.

As tendências históricas (ao longo dos anos) da associação entre origem e destino de classe, que define a desigualdade de oportunidades (fluidez social), podem ser influenciadas por quatro fatores: (1) mecanismo de equalização educacional definido pela associação entre origem de classe (O) e educação alcançada pelos filhos (E); (2) mecanismo de retornos educacionais definido pela associação entre educação (E) e classe de destino (D); (3) mecanismo de composição observado se a associação entre origem $(\mathrm{O})$ e destino de classes $(\mathrm{D})$ for menor nos níveis educacionais (E) mais altos (secundário e terciário) e se houver aumento percentual de pessoas nestes níveis ao longo dos anos; e (4) mecanismo de fluidez líquida definido pela associação direta, controlando por educação (E), entre classe de origem $(O)$ e de destino (D). Quando analisamos a associação entre origem e destino de classe (OD) sem controlar estatisticamente pela educação alcançada pelos filhos (E), não sabemos quais dos quatro mecanismos melhor explica as tendências da desigualdade de oportunidades. Ao longo deste artigo vamos utilizar uma série de modelos log-lineares para analisar o impacto destes quatro mecanismos nas tendências da fluidez social, e em seguida faremos algumas simulações para verificar qual dos quatro explica a maior parte da associação entre origem e destino.

\section{Modelos e Métodos}

Neste artigo analisamos a desigualdade de oportunidades de mobilidade social ou a fluidez social por meio de modelos log-lineares. Estes 
modelos são usados para estimar o padrão e a força da associação estatística entre origem e destino de classe. Esta associação é nossa medida de desigualdade de oportunidades. Mais especificamente usamos o modelo de interação completa para definir o padrão da associação entre origem e destino de classe (Powers e Xie, 2000). Ou seja, o padrão é definido pelo conjunto básico de razões de chances sem que nenhuma estrutura mais específica e simples - tal como um modelo topológico ou modelo de associação ordinal - seja definida. O padrão de associação completa permite capturar toda associação presente em cada tabela. Em cada análise apresentada organizamos os dados em tabelas distintas, agregando em torno de alguma variável, até finalmente analisarmos a tabela completa cruzando origem de classe $(\mathrm{O})$ por educação (E) por destino de classe (D) por período (P) - esta é a maior tabela analisada (ODEP), ou seja, uma tabela 6×6×6×5 contendo 1080 células. Reparem que analisamos os dados para homens e mulheres separadamente, i.e., não fazemos nenhuma comparação direta entre os sexos. As tabelas analisadas são: (1) origem $(\mathrm{O})$ por destino (D) de classe (sem distinguir educação) por período ( $\mathrm{P}$ ou ano da pesquisa) o que implica a Tabela ODP $(6 \times 6 \times 5)$, (2) origem de classe $(\mathrm{O})$ por educação (E) alcançada (sem distinguir classe de destino) por período (P) o que resulta na Tabela OEP $(6 \times 6 \times 5)$; (3) origem $(\mathrm{O})$ por destino de classe (D) por educação (E) o que leva à Tabela ODE (6×6×6); (4) educação (E) por destino (D) de classe (sem distinguir classe de origem) por período (P) o que corresponde à Tabela DEP (6x6x5); e (4) origem (O) por destino de classe (D) por educação (E) por período (P) o que implica a Tabela ODEP $(6 \times 6 \times 6 \times 5)^{7}$.

Para fazer as comparações ao longo dos anos (dos períodos, P) usamos duas formulações dos modelos log-lineares com padrão de associação completa. A primeira é o modelo de associação constante ao longo do tempo ou dos níveis educacionais, nos casos respectivamente de todas as tabelas que usam a variável para período (ano da pesquisa: 1973, $1982,1988,1996$ e 2008) e da tabela que usa a variável para níveis educacionais sem incluir período (Tabela ODE descrita acima). Se o modelo de associação constante, também denominado de modelo de fluidez constante, se ajustar bem aos dados de cada tabela, concluímos que não há mudança na força da associação ao longo to tempo ou entre os níveis educacionais (no caso da Tabela ODE). O segundo modelo que usamos é o "Unidiff"8 (Goldthorpe e Erickson, 1993) ou "modelo log-multiplicativo" (Xie, 1992) que estima um parâmetro ("unidiff") para período (no caso das tabelas incluindo período) ou para educação 
(no caso da Tabela ODE) que multiplica a associação entre origem e destino $(\mathrm{OD})$ ou entre origem e educação $(\mathrm{OE})$ ou entre destino e educação (DE), e assim redefine todas as razões de chances para cada ano estudado (todas as tabelas usando período) ou nível educacional (apenas para Tabela ODE). O parâmetro estimado "unidiff" pode ser interpretado como uma medida que multiplica a força da associação (todas as razões de chances). Este modelo "unidiff" pode ser especificado de duas formas: uma usando, por exemplo, P-1 graus de liberdade (ou seja, número de períodos, 5, menos 1 igual a 4 graus de liberdade), e outra definindo um padrão linear para o parâmetro Unidiff e usando, portanto, apenas um grau de liberdade. O segundo modelo é mais simples e tende a se ajustar melhor aos dados porque a linearidade é desenhada para se ajustar aos dados e apenas um grau de liberdade é usado. É preciso cautela para escolher entre estes dois modelos exatamente porque o segundo é confeccionado para se ajustar perfeitamente ao padrão de mudanças ao longo do tempo.

No caso das comparações entre 1973 e 2008, se o modelo "log-multiplicativo" (Unidiff-P ou Unidiff-P-linear) se ajustar melhor do que o modelo de fluidez constante e o estimador "unidiff" diminuir ao longo dos anos estudados, é possível afirmar que houve diminuição da força da associação entre origem e destino de classe. Em outras palavras, podemos afirmar que houve diminuição da desigualdade de oportunidades ou aumento da fluidez social.

As análises estatísticas usando modelos log-lineares apresentadas abaixo são feitas principalmente a partir da avaliação dos ajustes dos modelos de fluidez constante e "unidiff" ou "log-multiplicativo" aos dados das diversas tabelas. O modelo que melhor se ajustar aos dados será escolhido e usado para interpretar as tendências da desigualdade de oportunidades (fluidez social). Para avaliar o ajuste dos modelos usamos três métodos: (1) a estatística $L^{2}$, ou razão de verossimilhança, que se distribui como qui-quadrado $\left(\chi^{2}\right)$; c(2) a comparação hierárquica dos modelos aninhados (o modelo "unidiff" é mais completo do que o modelo de fluidez constante) usando as diferenças das estatísticas $\mathrm{L}^{2}$ e dos graus de liberdade dos modelos aninhados ou as diferenças das estatísticas BIC; e (3) o ajuste de acordo com a estatística BIC, quanto mais negativo o valor de BIC melhor o ajuste do modelo aos dados. A estatística BIC foi desenvolvida para possibilitar a avaliação do ajuste de modelos quando o número de casos nas amostras analisadas é muito grande (Raftery, 1986; 1995), tendo em vista que as estatísticas $L^{2}$ e $\chi^{2}$ 
são muito sensíveis ao tamanho das amostras, ou seja, dificultam a seleção de modelos bons quando as amostras são muito grandes. Nos dados que analisamos aqui é exatamente isto que ocorre, uma vez que as amostras totais são enormes, mais especificamente 214.921 casos para homens e 59.627 para mulheres quando comparamos as cinco pesquisas analisadas. Portanto, a estatística BIC será amplamente utilizada. É importante saber que uma diferença de pelo menos -5 pontos entre os BICs de dois modelos não permite determinar qual dos dois se ajusta melhor aos dados (Weakliem, 1999).

A partir da definição de qual dos dois modelos (fluidez constante ou unidiff) melhor se ajusta aos dados, podemos concluir se há ou não mudança na força da associação ao longo dos anos. Caso o segundo modelo se ajuste melhor devemos avaliar em que direção os estimadores "unidiff" seguem para concluir se há diminuição ou aumento da desigualdade de oportunidades ao longo dos anos estudados. Os modelos que usamos permitem definir mudanças na força da associação simultaneamente para diferentes combinações entre origem (O), destino (D) e educação (E) ao longo dos anos ou períodos analisados (P). Ou seja, podemos estimar modelos em que a associação OD, DE e OE variem simultaneamente ao longo de P. Os parâmetros "unidiff" para diferentes combinações de O, D e E ao longo de P são estimado a partir dos dados, ou seja, os dados podem revelar se há ou não mudança na força das associações e em que direção (aumento ou diminuição) a mudança ocorre.

\section{MOBILIDADE SOCIAL: TAXAS ABSOLUTAS}

Antes de analisar na próxima seção as tendências na "desigualdade de oportunidades de mobilidade social" (que por vezes também é chamada de "fluidez social" ou "taxas relativas de mobilidade"), apresentamos brevemente as "taxas absolutas de mobilidade". Ou seja, o total de mobilidade e as principais tendências agregadas. Estas taxas agregadas, que são apenas cálculos percentuais usando as tabelas de mobilidade, não dizem nada sobre as desigualdades de oportunidades, mas apenas indicam os principais movimentos populacionais. São, na realidade, uma maneira de descrever as distribuições das variáveis que analisamos: classes de origem, classes de destino, educação, sexo e período (ou ano da pesquisa). 
As principais distribuições percentuais das variáveis de classes de origem e destino (usando o esquema de seis classes), bem como de qualificação educacional, são apresentadas na Tabela 1 para homens e mulheres. Antes de começar a descrição, obviamente sucinta, destes dados, é importante lembrar que estamos tratando de grupos de classe ou ocupacionais bastante agregados. Se utilizássemos uma classificação mais desagregada (com mais categorias) ou dados contínuos (como status ocupacional ou renda), teríamos variação dentro de cada uma das categorias de classe. De qualquer forma, as tendências gerais parecem ser as mesmas e a comparação ao longo do tempo se torna mais simplificada ao usarmos poucas categorias. Além disso, teríamos problemas de tabelas com muitos zeros caso usássemos mais categorias.

Os dados da Tabela 1 indicam claramente que houve uma enorme mudança nas distribuições de destino quando comparadas com as de origem de classe. De um modo geral podemos dizer que em todos os anos observamos o aumento entre gerações das classes urbanas (I-II, IIIab, IVab, V-VI e VIIa) em relação à classe de trabalhadores rurais (VIIb-IVc), o que é uma consequência direta da rápida industrialização brasileira. Além disso, observamos uma mudança semelhante ao longo dos anos. Por exemplo, em 1973 apenas $11,6 \%$ dos homens e 11,1\% das mulheres estavam na classe de profissionais e administradores (I-II), número que passou respectivamente para 14\% e 14,8\% em 2008 esta mudança corresponde a um crescimento de $20 \%$ no tamanho da classe I-II. Em contrapartida, o percentual de pessoas com origem nas classes rurais diminuiu significativamente ao longo dos anos, o que correspondeu a um aumento considerável de pessoas com origem nas classes urbanas (todas menos a VIIb-IVc). Há diversas maneiras de resumir estas mudanças percentuais, ou taxas absolutas de mobilidade social. A mais simples e direta, no entanto, parece ser o índice de mobilidade intergeracional total. Esse número mede o percentual total de pessoas que estão em uma classe de destino diferente de sua classe de origem. A mobilidade total para homens foi de 55,3\% em 1973; 57,7\% em 1982; 60,7\% em 1988; 60,9\% em 1996; e 67,3\% em 2008. Para mulheres o índice de mobilidade total foi de 57,5\% em 1973; 67,7\% em 1982; $71,3 \%$ em 1988; 67,4\% em 1996, e 75,4\% em 2008. Embora estes números sejam influenciados pelo número de classes que estamos usando, se houvesse mais classes os números seriam mais altos, o fato importante é a tendência de expansão da mobilidade total. Independentemente do esquema usado houve, de fato, um enorme aumento da mobilidade total de homens e mulheres no Brasil entre 1973 e 2008. É importante lem- 


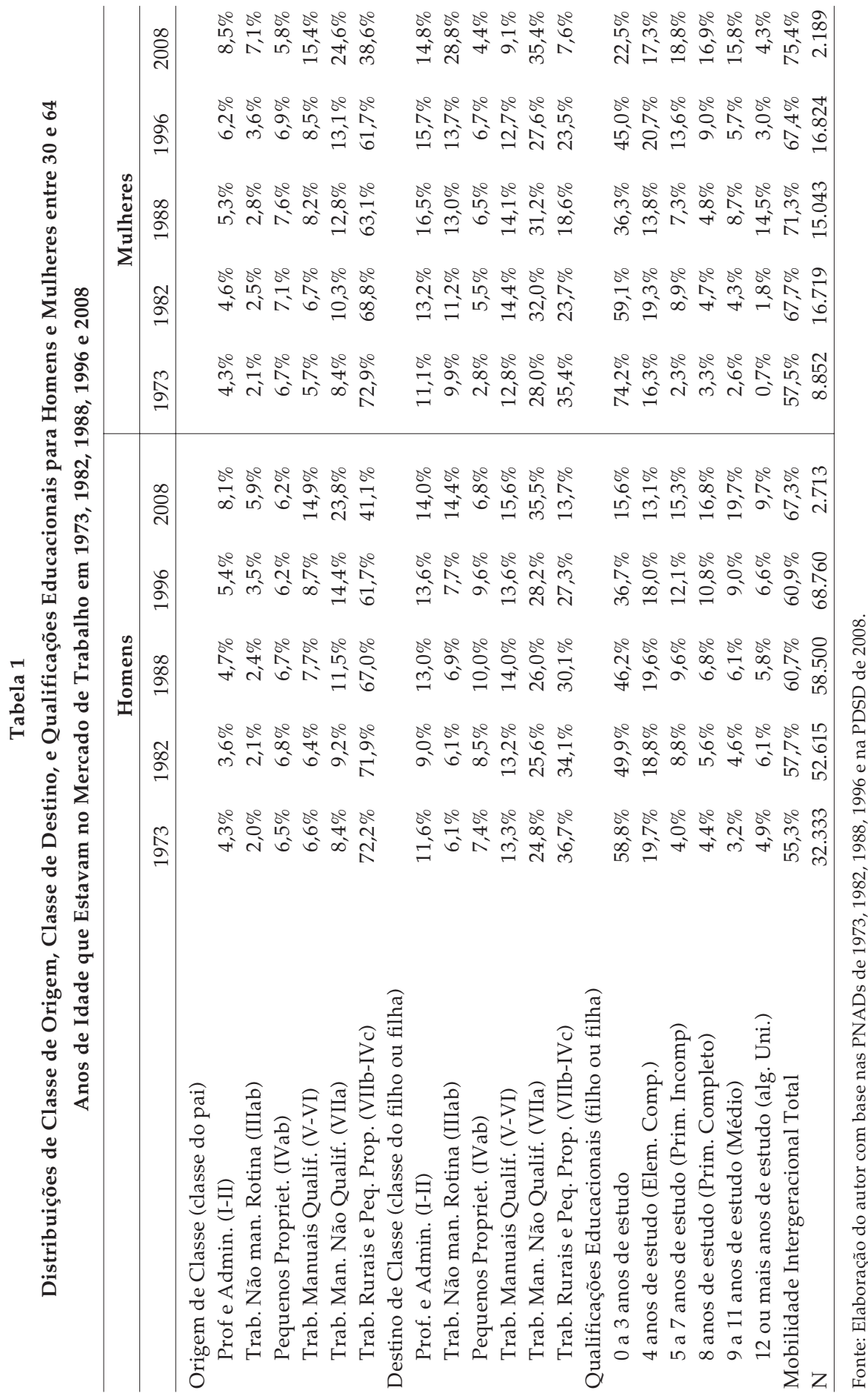


brar que os percentuais de mobilidade total de homens e mulheres não devem ser diretamente comparados, porque no caso das mulheres estamos medindo apenas aquelas que estavam no mercado de trabalho. Tendo em vista que ao longo do período houve uma enorme expansão da participação feminina no mercado de trabalho, não faz muito sentido comparar as taxas totais para homens e mulheres. Além disso, tanto para homens quanto para mulheres estamos usando a ocupação do pai para medir classe de origem, o que implica, no caso das mulheres, uma comparação entre ocupações masculinas (dos pais) e femininas (das filhas) levando a um aumento artificial da mobilidade total das mulheres porque há diferença estrutural na participação de homens (pais) e mulheres (filhas) no mercado de trabalho.

Na Tabela 1 também apresentamos a distribuição de qualificação educacional ao longo das últimas quatro décadas para homens e mulheres. Os dados revelam uma impressionante expansão educacional. Em $1973,58,8 \%$ dos homens e $74,2 \%$ das mulheres de 30 a 64 anos não tinham completado as quatro primeiras séries do ensino fundamental. Em 2008, estes números haviam diminuído para 15,2\% dos homens e $22,5 \%$ das mulheres ${ }^{9}$. Em contrapartida, houve uma enorme expansão do percentual de homens e mulheres com educação primária, secundária e superior. Ao analisarmos as tendências históricas na desigualdade de oportunidades educacionais vamos testar os possíveis impactos dessa expansão educacional.

\section{EXPLICANDO AS TENDÊNCIAS HISTÓRICAS DA DESIGUALDADE DE OPORTUNIDADES}

Para analisar as tendências históricas da desigualdade de oportunidades no Brasil examinamos mudanças na força da associação estatística entre a classe de origem dos homens e das mulheres, definida pela ocupação de seus pais, e a classe de destino em que se encontram na sua vida adulta, definida por sua ocupação. Quanto mais forte for a associação entre classe de origem e de destino, maior a desigualdade de oportunidades ou, inversamente, menor a fluidez social.

Na Tabela 2 apresentamos as estatísticas de ajuste de dois modelos log-lineares às tabelas cruzando classes de origem por classes de destino por período (1973, 1982, 1988, 1996 e 2008) para homens e para mulheres entre 30 e 64 anos de idade (Tabelas ODP). O primeiro modelo (fluidez constante) testa a hipótese de que a associação entre origem e 
destino é constante, não muda, ao longo dos cinco anos estudados. Ao passo que o segundo permite que a força da associação entre origem e destino varie livremente ao longo dos cinco anos. De acordo com a estatística BIC (quanto mais negativa melhor o ajuste), o segundo modelo se ajusta significativamente melhor aos dados para homens $\left(\mathrm{L}^{2}=\right.$ 283,9; g.1. $=96$ e BIC $=-858,1)$ e para mulheres $\left(L^{2}=200,3\right.$; g.1. $=96$ e $\mathrm{BIC}=-866,3$ ) do que o primeiro modelo (homens: $\mathrm{L}^{2}=343,1 ; \mathrm{g} .1 .=100 \mathrm{e}$ $\mathrm{BIC}=-846,6$; mulheres: $\mathrm{L}^{2}=325,3$; g.l. $=100$ e $\left.\mathrm{BIC}=-785,7\right)$. Tendo em vista que o segundo modelo revela que a força da associação entre origem e destino de classe diminuiu significativamente tanto para homens quanto para mulheres entre 1973 e 2008, podemos concluir que há diminuição da desigualdade de oportunidades. Os parâmetros "unidiff", que representam a força da associação entre classes de origem e destino, diminuem constantemente entre 1973 e 2008. Há uma diminuição de $19 \%$ (1 para 0,82$)$ para homens e de $25 \%$ (1 para 0,74$)$ para mulheres na associação entre origem e destino de classe, ou seja, em 2008 a origem de classe dos homens e das mulheres explicava menos seu destino de classe do que em 1973.

Tabela 2

Análise da Tabela Cruzando Origem por Destino de Classe por Período (ODP).

Homens e Mulheres entre 30 e 64 anos, Brasil: 1973, 1982, 1988, 1996 e 2008

\begin{tabular}{|c|c|c|c|c|c|c|c|c|c|}
\hline & \multicolumn{5}{|c|}{ Homens } & \multicolumn{4}{|c|}{ Mulheres } \\
\hline & $\mathrm{L} 2$ & g.l. & $\mathrm{BIC}$ & & & $\mathrm{L} 2$ & g.l. BIC & & \\
\hline ODP fluidez constante & 343,1 & 100 & $-846,6$ & & & 325,3 & $100-785,7$ & & \\
\hline \multirow[t]{3}{*}{ OD-unidiff-P } & 283,9 & 96 & $-858,1$ & & & 200,3 & $96-866,3$ & & \\
\hline & $\underline{1973}$ & $\underline{1982}$ & $\underline{1988}$ & $\underline{1996}$ & $\underline{2008}$ & $\underline{1973}$ & $\underline{1982} \underline{1988}$ & $\underline{1996}$ & $\underline{2008}$ \\
\hline & 1 & 0,97 & 0,92 & 0,90 & 0,82 & 1 & 0,94 & 0,78 & 0,74 \\
\hline \multirow[t]{3}{*}{ OD-unidiff-P linear } & 290,2 & 99 & $-887,5$ & & & 200,4 & $99-899,5$ & & \\
\hline & $\underline{1973}$ & $\underline{1982}$ & $\underline{1988}$ & $\underline{1996}$ & $\underline{2008}$ & $\underline{1973}$ & $\underline{1982 \underline{1988}}$ & $\underline{1996}$ & $\underline{2008}$ \\
\hline & 1 & 1 & 0,93 & 0,93 & 0,86 & 1 & 0,95 & 0,80 & 0,75 \\
\hline
\end{tabular}

Fonte: Elaboração do autor com base nas PNADs de 1973, 1982, 1988, 1996 e na PDSD de 2008.

As conclusões das análises acima devem ser apreciadas com cautela porque não controlam a associação entre origem e destino de classe pelo nível educacional alcançado pelos indivíduos. Tendo em vista que a educação é o principal mecanismo de mobilidade social, a ligação entre origem e destino de classes pode ser consequência de quatro mecanismos distintos envolvendo as associações entre origem $(\mathrm{O})$, 
destino (D) e educação (E). O primeiro é o mecanismo de equalização, que ocorre quando há uma diminuição na associação entre origem de classe e qualificações educacionais alcançadas (associação OE), ou seja, quando há uma diminuição da desigualdade de oportunidades educacionais ou das vantagens de classe no acesso e progressão dentro do sistema educacional. Todos os estudos sobre este tema para o caso brasileiro indicam que este tipo de desigualdade não mudou ao longo do tempo (Hasenbalg, 1999; Fernandes, 2001; Hasenbalg e Silva, 2003; Ribeiro, 2009, 2011), o que nos leva a duvidar da relevância deste mecanismo. O segundo é o mecanismo de composição, que ocorre se houver uma expansão muito grande dos níveis educacionais mais altos (ensino médio e universitário) e se a associação entre origem e destino de classe for mais fraca nestes níveis mais altos (análise da Tabela ODE). Um estudo anterior usando os dados até 1996 indica que este não é o principal mecanismo (Torche e Ribeiro, 2010), como estamos usando os mesmos dados apenas acrescentando mais um ano (2008) também esperamos que este não seja o principal mecanismo. A terceira explicação seria dada pelo mecanismo de retornos decrescentes à educação. Esse processo se dá quando a associação entre educação alcançada e destino de classe (associação ED) diminui, o que deve ser interpretado como uma evidência de que as vantagens educacionais para a mobilidade social estão diminuindo. Substantivamente isso significa que as vantagens conferidas por diplomas educacionais no acesso a posições de classe mais altas estão diminuindo. Historicamente estas vantagens têm sido excessivamente altas no Brasil, porque há um percentual pequeno de pessoas com níveis educacionais mais altos. Este mecanismo é o principal fator explicando a diminuição da associação entre origem e destino de classe de 1988 a 1996 (Torche e Ribeiro, 2010). As análises no presente artigo permitem observar se esta tendência continuou presente entre 1996 e 2008. Finalmente, pode haver uma diminuição da associação direta entre origem e destino de classe controlando por educação, ou seja, a associação descontando o efeito da educação. Estas vantagens e desvantagens diretas podem ser expressão de diversos processos sociais tais como: discriminação de pessoas com origens em certas classes, redes de conhecimento pessoal favorecendo pessoas com diferentes origens, ou até mesmo diferenças de motivação entre indivíduos. Havendo uma diminuição destas diferenças teríamos o mecanismo de aumento da fluidez líquida.

Para testar a relevância dos três primeiros mecanismos ajustamos uma série de modelos log-lineares às três tabelas diferentes para o período 


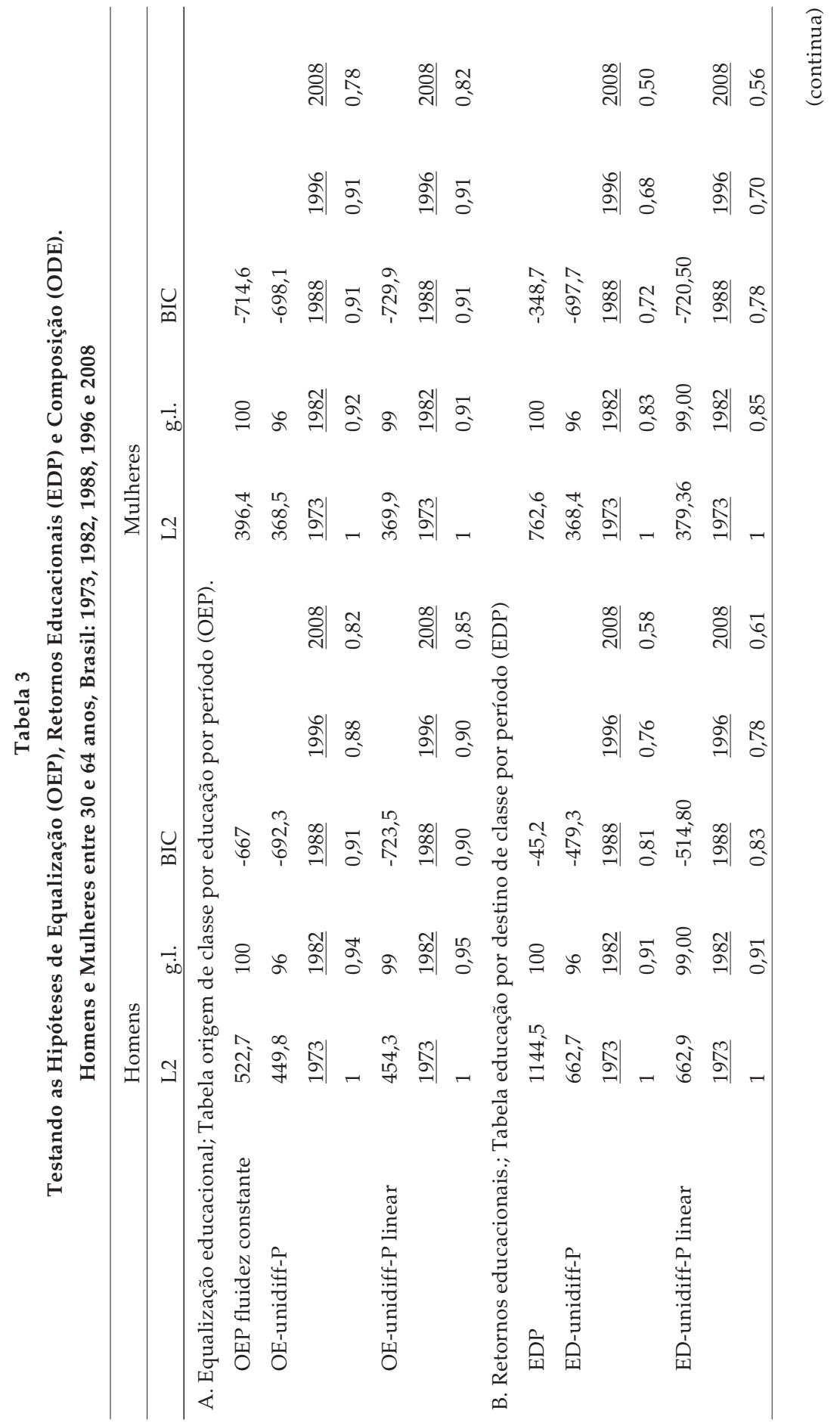


Quatro Décadas de Mobilidade Social no Brasil

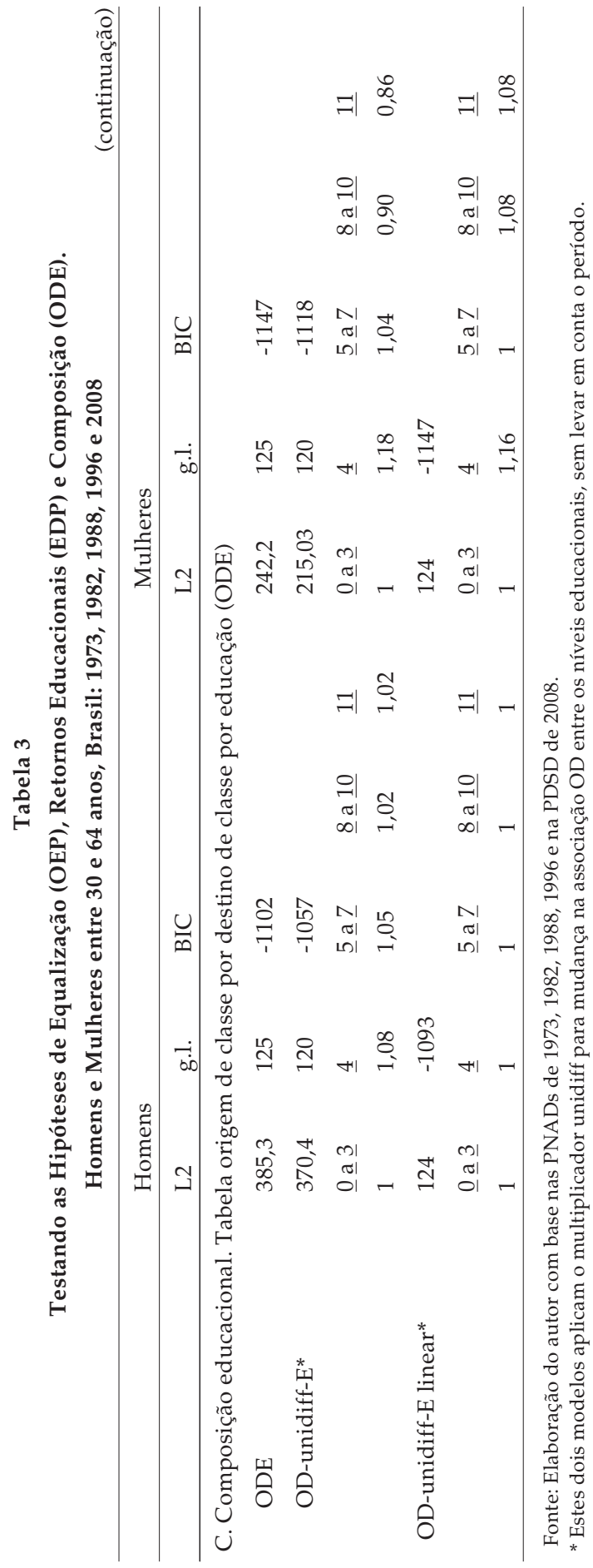


de 1973 a 2008. Os ajustes destes modelos, bem como os parâmetros "unidiff" mensurando tendências ao longo do período, são apresentados na Tabela 3. Para testar a relevância dos três primeiros mecanismos em conjunto com o quarto, estimamos outro conjunto de modelos log-lineares, cujos ajustes e principais parâmetros estimados são apresentados na Tabela 4.

Na parte A da Tabela 3 são apresentados os ajustes de dois modelos (fluidez constante e "unidiff") à tabela cruzando origem de classe por educação alcançada por período (Tabela OEP). Aqui o objetivo é testar o mecanismo de equalização, ou seja, verificar se há diminuição da desigualdade de oportunidades educacionais entre 1973 e 2008. De acordo com a estatística BIC, o modelo "unidiff", deixando a associação OE variar ao longo do tempo, se ajusta melhor aos dados para homens $\left(\mathrm{L}^{2}\right.$ $=449,8 ;$ g.l. $=96$ e BIC $=-692)$ do que o modelo de fluidez constante $\left(\mathrm{L}^{2}=\right.$ 552,7; g.1. = 100 e BIC = -667). Isto significa que devemos concluir não apenas que a associação entre origem de classe e educação alcançada (OE) diminuiu entre 1973 e 2008, mas também que o mecanismo de equalização poderia explicar parte da diminuição da desigualdade de oportunidades (diminuição da associação OD). No entanto, análises usando apenas os dados para o período de 1973 a 1996 indicam que o modelo de fluidez constante se ajusta melhor. Estes resultados sugerem que a mudança na associação OE ocorreu principalmente entre 1996 e 2008. Para as mulheres a conclusão é diferente, uma vez que o modelo de fluidez constante $\left(\mathrm{L}^{2}=396,4\right.$; g.l. $=100$ e BIC $\left.=-714\right)$ se ajusta melhor aos dados do que o "unidiff" ( $\mathrm{L}^{2}=368,5$; g.l. = 96 e BIC = -698). Embora as evidências sejam de que não há diminuição da desigualdade de oportunidades educacionais (OE) para mulheres entre 1973 e 2008, os parâmetros "unidiff" estimados indicam que há uma forte tendência de diminuição da associação OE entre 1996 e 2008 - o parâmetro estimado diminuiu de 0,91 para 0,78 o que representaria uma diminuição considerável na força da associação OE. Estes resultados indicam que o mecanismo de equalização não deve ser parte da explicação sobre o aumento da fluidez das mulheres entre 1973 e 1996, mas que pode ter alguma relevância para o período de 1996 a 2008.

Na parte B da Tabela 3 apresentamos o ajuste dos modelos usados para testar a relevância do mecanismo de retornos decrescentes à educação. Com este propósito ajustamos dois modelos à Tabela cruzando educação alcançada por destino de classe por período (tabela EDP): um primeiro para verificar se a associação ED é constante, e um segundo deixando 
esta associação se modificar ao longo do período. Neste caso o segundo modelo se ajusta muito melhor do que o primeiro para homens $\left(\mathrm{L}^{2}=\right.$ 662,7; g.l. = 96 e BIC = -479) e para mulheres $\left(\mathrm{L}^{2}=368\right.$; g.1. = 96 e BIC = -697,7). Portanto, devemos concluir que há mudança significativa na associação ED ao longo do tempo. De fato, há uma diminuição de $42 \%$ (de 1 para 0,58) para homens e $50 \%$ (de 1 para 0,50 ) para mulheres na força da associação entre educação alcançada (E) e destino de classe (D). Em outras palavras, há redução bastante significativa dos retornos educacionais no Brasil entre 1973 e 2008, mas principalmente para o período mais recente entre 1996 e 2008.

Este último resultado sugere que a expansão educacional do ensino médio e superior (ver Tabela 1) levou a uma redução do prêmio de classe (equivalente à redução do prêmio salarial) obtido pelas qualificações educacionais no Brasil. Talvez seja exagerado dizer que houve uma inflação de credenciais, tendo em vista que o país ainda é muito carente em termos educacionais, mas certamente houve uma diminuição dos retornos educacionais quando pensados em termos globais como estamos fazendo neste artigo. Provavelmente há alguma forma de estratificação dentro dos próprios sistemas educacionais fazendo com que os retornos às qualificações variem entre tipos de escola e de área de formação no ensino médio e no universitário. Alguns estudos revelam que há enorme estratificação entre escolas públicas e privadas de ensino médio (Albanez, Ferreira e Franco, 2002; Albernaz, Ferreira e Franco, 2002; Alvez, 2007), e entre universidades e áreas de formação seletivas e não seletivas de ensino superior (Mello, 2011). Como estamos observando os retornos médios e como houve expansão de escolas e universidades de menor qualidade, faz sentido interpretar as evidências mostrando a relevância do mecanismo de declínio nos retornos educacionais como um importante fator contribuindo para a diminuição da associação entre classes de origem e de destino. Em outras palavras, as evidências indicam que os retornos decrescentes à educação são parte da história para explicar o declínio da associação entre origem e destino de classe quando levamos em conta o nível educacional alcançado.

Finalmente, na parte $\mathrm{C}$ da Tabela 3 apresentamos o ajuste de modelos que testam o poder explicativo do mecanismo de composição. Para tanto fazemos comparações entre dois modelos log-lineares ajustados à tabela cruzando origem por destino de classe por nível educacional alcançado (Tabela ODE). O primeiro modelo testa a hipótese de que a associação OD não varia entre os diferentes níveis educacionais, ou seja, 
a associação entre origem e destino de classe seria independente do nível educacional alcançado, ou, em outras palavras, seria igual em todos os níveis educacionais. Já o segundo modelo permite que a força da associação OD seja diferente em cada nível educacional. De acordo com a estatística BIC o primeiro modelo se ajusta significativamente melhor aos dados tanto para homens $\left(\mathrm{L}^{2}=370 ; \mathrm{g} .1 .=125\right.$; e $\left.\mathrm{BIC}=-1102\right)$ quanto para mulheres $\left(\mathrm{L}^{2}=242\right.$; g.l. $=125$; e $\left.\mathrm{BIC}=-1147\right)$ do que o segundo (homens: $\mathrm{L}^{2}=370$; g.l. = 120; e BIC = -1057; mulheres: $\mathrm{L}^{2}=215$; g.l. = 120; e BIC = -1118). Em suma, o mecanismo de composição não pode ser usado para explicar o declínio da associação entre origem e destino de classe entre 1973 e 2008. Embora tenha havido uma enorme expansão educacional - por exemplo, em 1973 apenas 8,1\% dos homens e $3,3 \%$ das mulheres tinham segundo grau completo ou mais, ao passo que em 2008 esses números eram 29,4\% e 20,1\% respectivamente (ver Tabela 1) - as vantagens de classe parecem ser semelhantes em todos os níveis educacionais.

As análises apresentadas acima sugerem fortemente que há um declínio nos retornos de classe às qualificações educacionais ao longo dos anos e indicam a possibilidade de alguma equalização educacional para homens e mulheres entre 1996 e 2008, mas não fornecem evidências de que o mecanismo de composição seja relevante. No entanto, para testar de forma mais completa a influência das diversas ligações entre origem e destino de classe (apresentadas na Figura 1) nas tendências da fluidez social, analisamos a seguir as tabelas para homens e mulheres cruzando origem por destino por educação por período (Tabelas ODEP).

A Tabela 4 apresenta modelos estimados para testar as tendências de mudança na associação intergeracional de classes levando em conta os mecanismos de equalização, composição e declínio nos retornos educacionais. O primeiro modelo testa a hipótese de que as associações $\mathrm{OE}$ (origem-educação), ED (educação-destino) e OD (origem-destino) não mudam ao longo do tempo. Este modelo serve como base para a comparação com os seguintes. Os outros modelos testam mudanças (em forma "log-multiplicativa" ou "unidiff") nos diferentes caminhos ligando origem a destino de classe passando por educação. O Modelo 2 deixa a associação entre origem de classe e educação alcançada (OE) variar ao longo do tempo, o que não melhora o ajuste em relação ao Modelo 1 para mulheres e indica uma possibilidade de ajuste melhor aos dados dos homens. No entanto, como a diferença no BIC é de ape- 


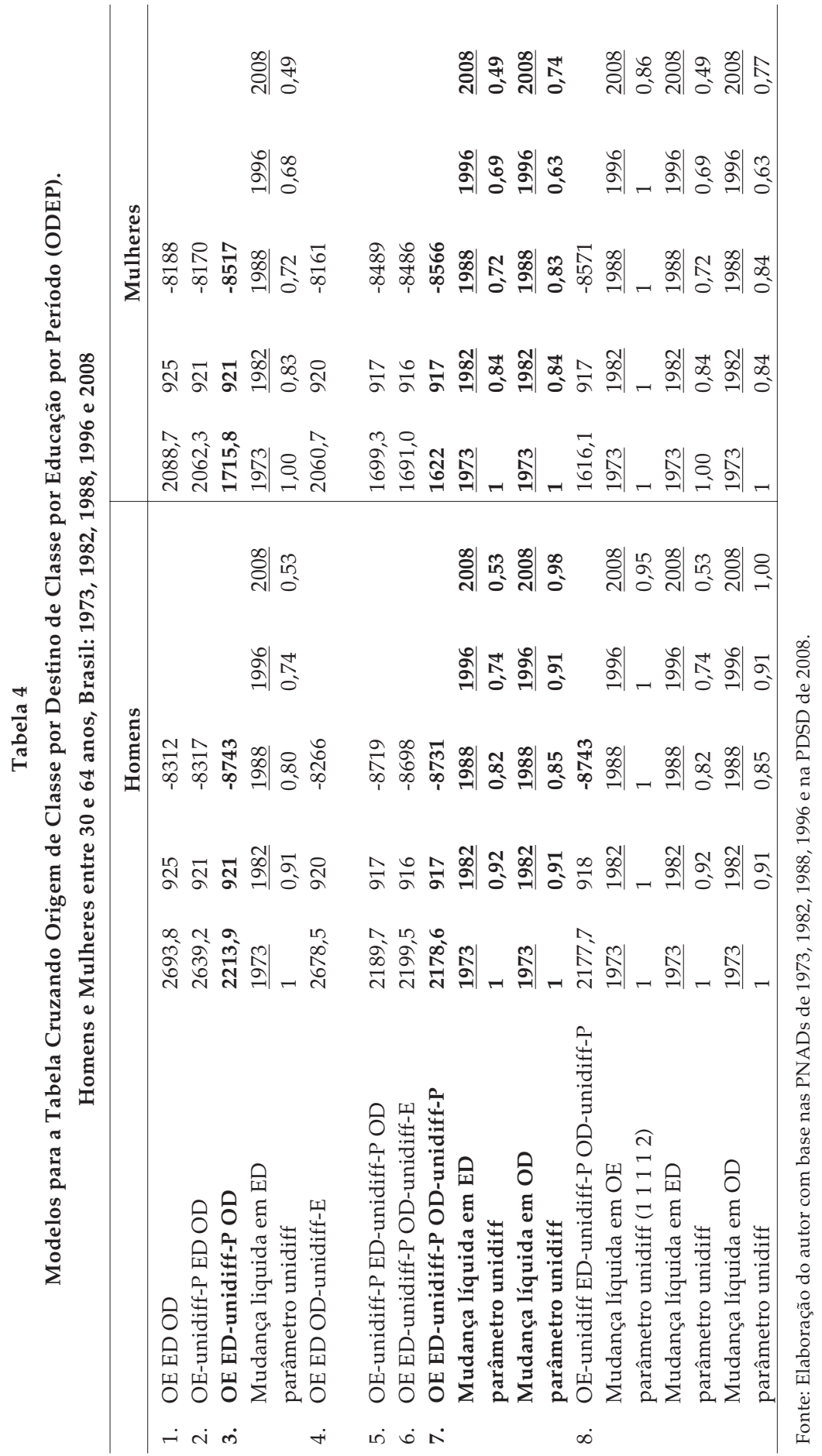


nas 5 pontos não podemos afirmar com certeza que o Modelo 2 é melhor do que o Modelo 1 para os homens - de acordo com Weakliem (1999) uma diferença de 5 pontos no BIC é duvidosa para decidir qual o melhor modelo. Estes resultados indicam que as mudanças na ligação entre classe de origem e educação $(\mathrm{OE})$ são pequenas.

O Modelo 3 permite que haja variação ao longo dos anos na associação entre educação e destino de classe (ED). Uma vez que observamos mudanças significativas nos retornos à educação, não surpreende o fato de o Modelo 3 se ajustar bem melhor do que os anteriores aos dados para homens e mulheres. Finalmente, o Modelo 4 verifica se há variação da associação OD (origem-destino) ao longo dos níveis escolares, o que poderia revelar um efeito de composição, mas não resulta em um melhor ajuste para os homens nem para as mulheres. Estas análises sugerem que o único componente do papel interveniente da educação que muda ao longo do tempo no Brasil é o de retornos de classe às qualificações educacionais (associação ED). Os Modelos 5 e 6 reforçam ainda mais esta conclusão na medida em que acrescentam à variação ao longo do período (P) em ED (educação-destino) a variação ao longo de P em OE (Modelo 5) e a variação ao longo dos níveis educacionais (E) na associação entre origem e destino, OD (Modelo 6). Nenhum dos dois (Modelos 5 e 6) melhora o ajuste em relação ao Modelo 3, ou seja, $a$ diminuição dos retornos educacionais parece explicar completamente o aumento da fluidez social entre 1973 e 2008.

Mas ainda há um tipo de associação intergeracional que não passa pela educação: a associação direta entre classes de origem e de destino, descontando o efeito de educação (associação OD independente de E). Esta associação é consequência de transferências diretas de classe tais como capital cultural, redes sociais e outras formas de favorecimento. O Modelo 7 testa esta hipótese acrescentando ao Modelo 3, o preferido entre os anteriores, a possibilidade de variação ao longo do tempo (P) da associação direta, descontando a mediação da educação, entre origem e destino de classe (OD |E, associação origem-destino independente de educação). Este Modelo 7 melhora significativamente o ajuste em relação ao Modelo 3 tanto para homens quanto para mulheres mostrando, portanto, que além da diminuição dos retornos educacionais há uma tendência de mudança na associação direta entre origem e destino de classe.

Tendo em vista que observamos alguma tendência de diminuição da associação entre origem e educação (OE) para o período de 1996 a 2008, 
que não havia sido estudado anteriormente, ajustamos um último modelo aos dados. O Modelo 8 permite que a força da associação OE (origem-educação) varie entre 1996 e 2008, e simplifica as tendências temporais da associação OD (origem-destino) e ED (educação-destino). Este modelo se ajusta ainda melhor do que todos os anteriores. É difícil decidir qual o melhor modelo, o 7 ou o 8 . O Modelo 7 indica mudanças temporais livres em ED (educação-destino) e OD (origem-destino), enquanto o Modelo 8 simplifica artificialmente estas tendências uma vez que impõe um padrão linear (usando menos graus de liberdade) a estas associações. Em outras palavras, o Modelo 8 é desenhado para se ajustar melhor aos dados e para incluir a mudança temporal em $\mathrm{OE}$ (origem-educação). Tecnicamente o melhor seria o Modelo 7, mas substantivamente o Modelo 8 permite dizer que houve alguma mudança em OE (associação origem-educação) entre 1996 e 2008, conclusão já apontada pelas análises apresentadas na Tabela 3.

As conclusões alcançadas pelos Modelos 7 e 8 podem ser observadas graficamente nos Gráficos 1 e 2 que apresentam os coeficientes "unidiff", estimados por estes modelos, que são uma medida da mudança na força da associação ao longo do tempo. O Gráfico 1 apresenta as ten-

\section{Gráfico 1}

tendências da Fluidez Social no Brasil

Homens, 1973 a 2008

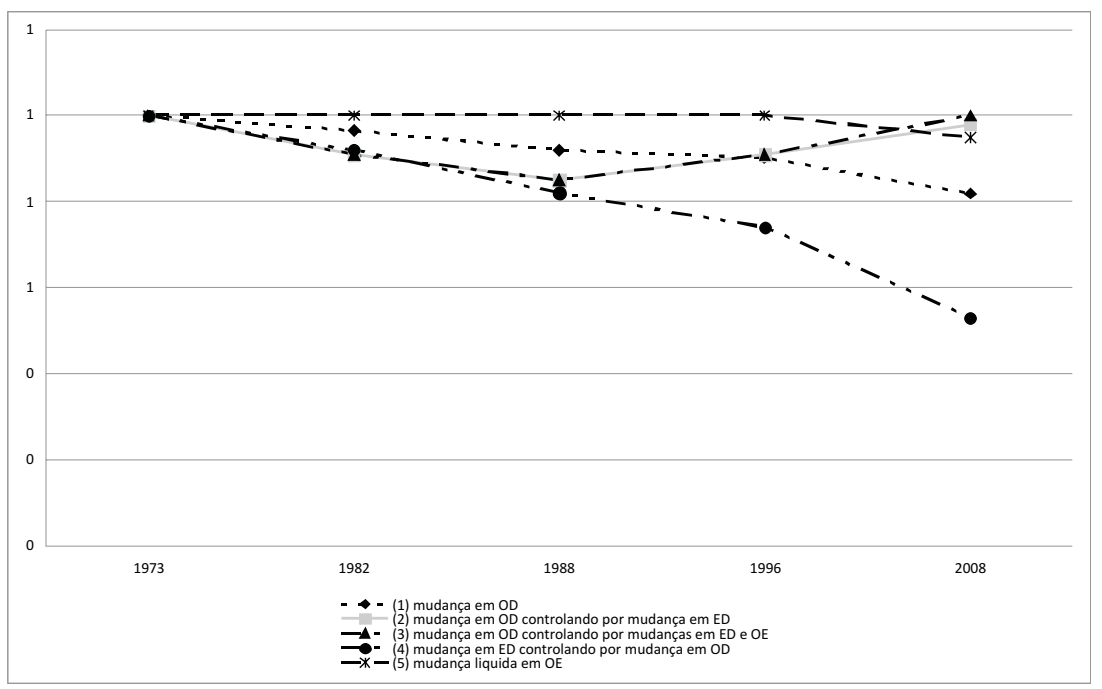

Elaboração do autor. 


\section{Gráfico 2}

Tendências da Fluidez Social no Brasil,

Mulheres, 1973 a 2008

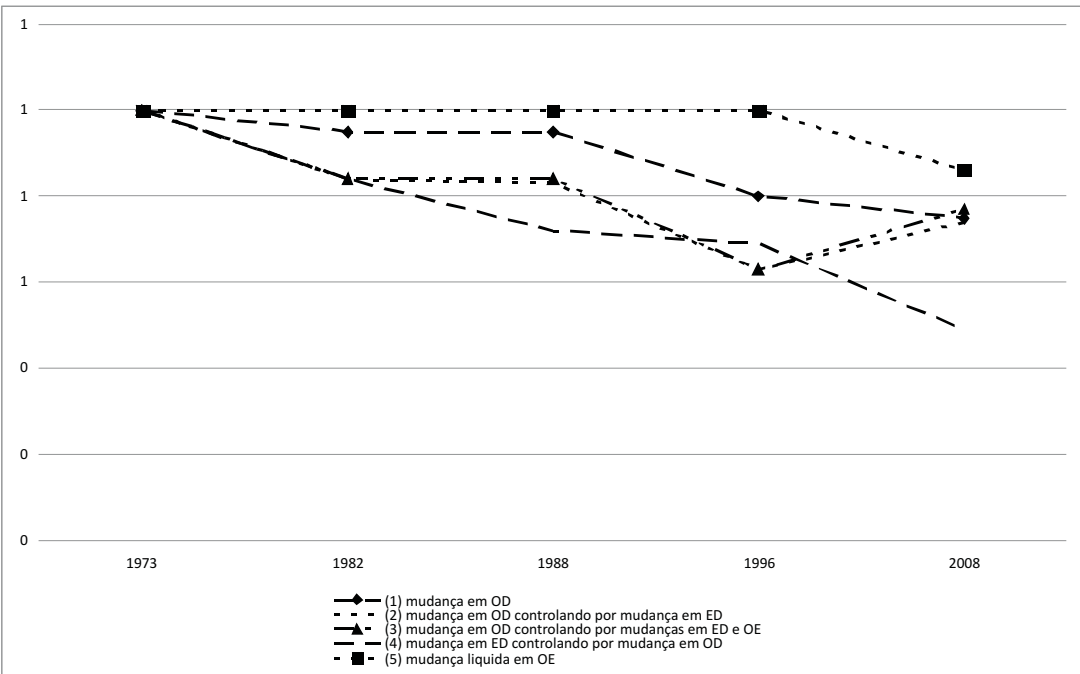

Elaboração do autor.

dências de diminuição da desigualdade de oportunidades para os homens no período estudado. As linhas do Gráfico 1 permitem observar os efeitos da diminuição na associação entre origem de classe e educação alcançada (OE) e entre educação alcançada e classe de destino (ED) nas tendências da desigualdade de oportunidades ou fluidez social no período estudado. A linha de tendência 1 (intitulada "mudança em OD" e obtida pelo modelo unidiff da Tabela 2) revela que a associação entre origem e destino de classe diminui constantemente entre 1973 e 2008, mas não controla pelo efeito da educação alcançada. Ao controlarmos por educação (linhas 2 e 3) verificamos que o efeito de origem de classe em destino de classe (OD) diminui entre 1973 e 1988, mas aumenta entre 1988 e 2008. Este aumento a partir de 1988 ocorre principalmente porque há uma diminuição da associação entre educação alcançada e destino de classe (ED), o que pode ser observado quando comparamos a linha de tendência 2 (mudança em OD controlando por mudança em ED) com a linha de tendência 4 (mudança em ED controlando por OD). A comparação entre estas duas linhas indica que a maior parte da diminuição da associação $O D$ (origem-destino, linha 1) é na realidade um reflexo da mudança em ED (educação-destino). Uma vez que controlamos por ED (educação-destino, linha 4), há, na realidade, um aumento da associa- 
ção OD (origem-destino) entre 1988 e 2008. Estes resultados são bastante significativos e complementares, ou seja, a diminuição da associação entre educação e destino de classe (ED) foi acompanhada pelo aumento da associação entre origem e destino de classe (OD) a partir de 1988.

Em outras palavras, quando levamos em conta a educação observamos que a diminuição da desigualdade de oportunidades global (associação OD, origem-destino, sem controlar por educação - modelo "unidiff" da Tabela 2) se deve a uma diminuição dos retornos educacionais (associação ED). Entre 1996 e 2008 também parece haver uma leve diminuição da associação entre origem de classe e educação alcançada $(\mathrm{OE})$, o que fica claro quando comparamos as linhas 1,3 e 5. Ou seja, há uma diminuição na associação OE (origem-educação, linha 5), que explica parte da diminuição da associação OD (origem-destino, linha 1), e que, quando levada em conta, revela um pequeno aumento da associação OD (origem-destino, linha 4) entre 1996 e 2008. Em outras palavras, quando levamos em conta a educação alcançada observamos que a tendência inicial de diminuição da associação global entre origem e destino (linha 1) se deve, de fato, a uma diminuição dos retornos educacionais (ED) a partir de 1988 e a uma leve diminuição da desigualdade de oportunidades educacionais (OE) a partir de 1996. Controlando por estes dois fatores observamos que, de fato, houve um aumento da associação líquida entre origem e destino (OD) a partir de 1988.

Para as mulheres as tendências de aumento da fluidez social (ou, inversamente, diminuição das desigualdades de oportunidades) são um pouco diferentes. Estas tendências são apresentadas no Gráfico 2. A linha de tendência 1 (intitulada "mudança em OD") revela que, sem controlar por educação, a associação entre origem e destino de classe (OD) diminui de 1973 a 1988, embora a diminuição tenha sido bem mais acentuada entre 1988 e 2008. Ao controlarmos por educação (linhas 2 e 3) verificamos que o efeito de origem de classe em destino de classe (OD) diminui entre 1973 e 1996, mas aumenta entre 1996 e 2008. Este aumento a partir de 1996 ocorre principalmente porque há uma diminuição da associação entre educação alcançada e destino de classe (ED) (linha 4), mas também porque há uma leve diminuição da associação entre origem de classe e educação alcançada (OE) (linha 5) entre 1996 e 2008. Uma vez que levamos em conta as associações ED (educação-destino) e OE (origem-educação), observamos um pequeno aumento da associação OD (associação líquida origem-destino líquida) entre 1996 e 2008. Em outras palavras, a diminuição da desigualdade de 
oportunidade se deve antes à diminuição da associação entre educação e destino de classe (ED) e origem de classe e educação (OE) do que a uma diminuição direta da associação entre classe de origem e destino de classe (OD), que na realidade aumenta a partir de 1996, quando controlamos por educação.

Em conjunto os Modelos 7 e 8 da Tabela 4 e os Gráficos 1 e 2 confirmam que as tendências de diminuição dos retornos educacionais, observadas para o período de 1973 a 1996 (Torche e Ribeiro, 2010), continuam até 2008 para os homens e também são válidas para as mulheres (o estudo anterior não utilizou dados para mulheres). A influência direta das classes de origem nas de destino decresce até 1988 e aumenta até 2008 para os homens e decresce até 1996 e aumenta até 2008 para as mulheres. Este último resultado é importante porque indica um aumento das vantagens de classe diretas, ou seja, uma vez que a educação élevada em conta, há um aumento da vantagem de classe (associação OD líquida, descontando educação) a partir de 1988 para homens e de 1996 para mulheres. Finalmente, o último modelo (8) permite dizer que talvez haja alguma diminuição na associação entre origem de classe e educação (OE) de 1996 a 2008.

\section{SIMULAÇÕES CONTRAFACTUAIS}

Os Modelos 7 e 8 explicam claramente o padrão de mudanças que levou ao aumento da fluidez social no Brasil entre 1973 e 2008. Mas para termos certeza sobre as principais causas do aumento da fluidez temos que dar mais um passo e realizar uma análise contrafactual. Ou seja, uma simulação para avaliar conjuntamente o tamanho do impacto de cada um dos três mecanismos envolvendo as qualificações educacionais e a associação líquida (controlando por educação) na diminuição global da desigualdade de oportunidades (associação OD, origemdestino, sem controlar por educação). Se tivéssemos usando modelos de regressão linear (ou outros semelhantes) poderíamos fazer essa decomposição a partir dos próprios estimadores do modelo (como é feito, por exemplo, em modelos de equações estruturais ou análises de trajetória), mas com modelos log-lineares a decomposição é mais complexa (veja Breen (2011) para uma explicação mais detalhada). Neste sentido, propomos quatro questões contrafactuais: (Simulação 1) Qual teria sido a mudança ao longo do tempo na associação global entre OD, na fluidez social, se não houvesse mudança na associação OD controlando por educação? (Simulação 2) Qual teria sido a mudança ao longo do tempo na associação global entre OD, na fluidez social, se não houvesse mudança na associação ED, se não houvesse diminuição dos retor- 
nos educacionais? (Simulação 3) Qual teria sido a mudança ao longo do tempo na associação global entre OD, na fluidez social, se não houvesse mudança na associação $\mathrm{OE}$, se não houvesse equalização educacional? (Simulação 4) Qual teria sido a mudança ao longo do tempo na associação global OD, fluidez social, se o mecanismo de composição não estivesse em jogo (associação ODE)?

Para realizar estas simulações utilizamos um método recentemente apresentado por Breen (2011). Este método consiste em simular frequências em tabelas de mobilidade que excluam o efeito que queremos testar em etapas, ou seja, a primeira simulação exclui o efeito OD controlando por $\mathrm{E}$, a segunda adiciona à primeira simulação a exclusão do efeito $\mathrm{ED}$, a terceira acrescenta às anteriores a exclusão do efeito $\mathrm{OE}$, e a quarta acrescenta a todas as anteriores a exclusão do efeito de composição (ODE). Usando estas quatro Tabelas ODP (origem por destino por período) de frequências simuladas, estimamos quatro modelos "unidiff", que deixam a associação OD variar livremente ao longo do tempo. A tendência observada a partir destas tabelas fictícias revela qual seria a mudança caso não houvesse o efeito excluído. Quando comparamos esta tendência excluindo os efeitos testados com a tendência observada podemos calcular qual o tamanho da contribuição dos efeitos que excluímos. Assim temos uma maneira de quantificar o percentual de contribuição de cada mecanismo, ou seja, dos mecanismos de fluidez líquida, de retornos educacionais, de equalização educacional e de composição sobre a tendência global de desigualdade de oportunidades. No Brasil sabemos que a tendência é de diminuição da desigualdade de oportunidades global (ver Tabela 2) e, de acordo com as análises apresentadas acima, sabemos que o mecanismo de diminuição dos retornos educacionais parece ser o mais importante. As simulações apresentadas na Tabela 5 não apenas confirmam os resultados anteriores, como também revelam qual o percentual da tendência global da fluidez social que é devido à diminuição da associação ED (educação-destino).

As simulações apresentadas na Tabela 5 revelam que apenas as tendências de diminuição da associação ED (educação-destino) e diminuição da associação OD (origem-destino, controlando por educação) estão relacionadas à diminuição global da desigualdade de oportunidades (dados observados). Para os homens, a mudança em OD controlando por educação (Simulação 1) explica 19,5\%, e a mudança em ED (Simulação 2) explica $29 \%$ da diminuição global da desigualdade de oportu- 
Carlos A. Costa Ribeiro

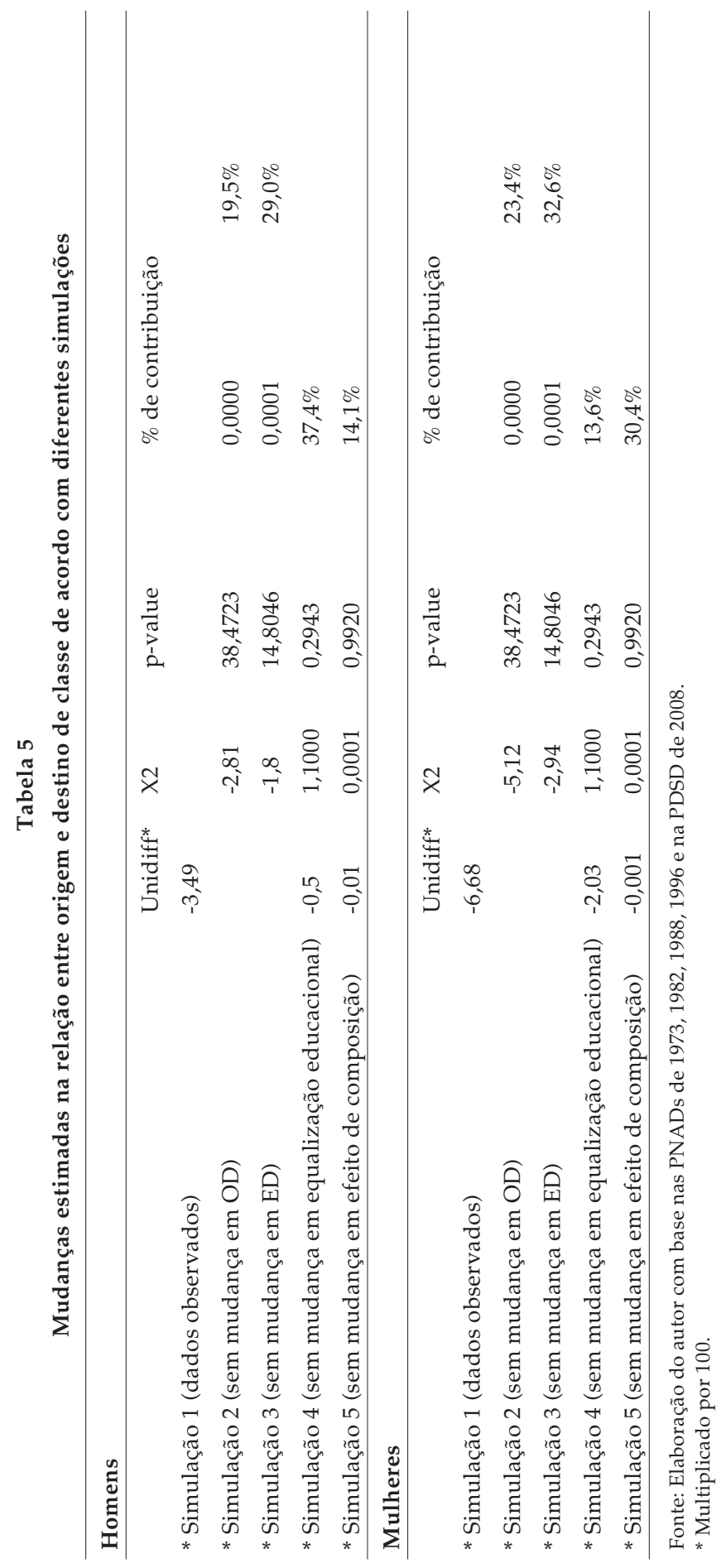


nidades. Os mecanismos de equalização (Simulação 3) e de composição (Simulação 4) não explicam a mudança global na desigualdade de oportunidades uma vez que as tendências estimadas não são significativamente diferentes de zero de acordo com o teste de qui-quadrado (colunas 3 e 4 da Tabela 5). Para as mulheres chegamos a uma conclusão semelhante, ou seja, $23 \%$ da diminuição global da desigualdade de oportunidades se deve à diminuição da associação líquida OD (origem-destino, controlando por educação) e 32,6\% à diminuição da associação ED (educação-destino). Tanto para homens como para mulheres é a diminuição dos retornos educacionais que mais explica a diminuição global da desigualdade de oportunidades ou, inversamente, o aumento global da fluidez social.

\section{CONCLUSÕES}

Neste artigo usamos dados de 2008 para completar uma série de quatro décadas de informações sobre mobilidade social e desigualdade de oportunidades no Brasil. Os estudos anteriores se baseavam em dados coletados entre 1973 e 1996 (Pastore e Silva, 2000; Ribeiro, 2007), e, portanto, não forneciam informações sobre o que ocorreu entre o final das décadas de 1990 e de 2000. Este período recente é altamente relevante por diversos motivos. Foi um período em que houve quatro governos eleitos democraticamente (dois de Fernando Henrique Cardoso e dois de Luiz Inácio Lula da Silva), que de maneiras diversas contribuíram para controlar os altos níveis de inflação que caracterizaram as décadas anteriores, diminuir o percentual de pobres no país, diminuir a desigualdade de renda, aumentar o acesso e progressão no sistema educacional, e retomar o crescimento econômico do país. Embora diversos analistas procurem legitimamente, ainda que por vezes com interesses políticos opostos, mostrar diferenças entre os governos FHC e Lula, no caso da mobilidade social intergeracional e da desigualdade de oportunidades nos parece mais conveniente avaliar o que ocorreu no período de forma conjunta. De fato, os possíveis impactos das mudanças e políticas descritas acima sobre a mobilidade e a desigualdade de oportunidades pensadas em termos intergeracionais devem ser avaliadas tomando o período em conjunto.

As análises apresentadas neste artigo para o período de meados da década de 1990 e década de 2000 revelaram algumas continuidades em relação ao período anteriormente estudado, por um lado, e indicaram algumas importantes mudanças de tendência desde 1996, por outro 
lado. Durante todo o período estudado, 1973 a 2008, a diminuição dos retornos educacionais parece ter sido o principal fator contribuindo para diminuir as desigualdades de oportunidades. Esta diminuição deve ser compreendida no contexto de rápida industrialização e baixa qualificação da mão de obra que caracterizou o desenvolvimento econômico do país. Nas décadas de 1960 e 1970 o Brasil se desenvolveu muito rápido e sua mão de obra era muito pouco qualificada, o que implicava um retorno excessivamente alto para qualificações educacionais de nível médio e superior. Com o tempo, a partir da década de 1980, houve uma expansão educacional que acabou por diminuir os retornos educacionais excessivos na medida em que contribuiu para aumentar a oferta de mão de obra qualificada. Portanto, faz sentido imaginar que haja uma diminuição dos retornos educacionais e que este processo esteja ligado à diminuição das desigualdades de oportunidades.

No entanto, a partir de 1988, para os homens, e de 1996, para as mulheres, esta diminuição dos retornos educacionais foi acompanhada por um aumento da influência direta, controlando por educação, da origem de classes no destino de classes. Essa tendência observada revela que, em um contexto de diminuição dos retornos educacionais, as famílias em posições de classe mais vantajosas foram capazes de garantir melhores condições de ascensão ou manutenção da posição de classe de seus filhos. Nossas análises revelam que, a partir do final da década de 1980, houve um aumento da associação líquida, descontando o efeito da educação alcançada, entre origem e destino de classe. Os dados são claros neste sentido, mas a interpretação destes resultados é mais complexa. Não há como saber exatamente que processo social estaria definindo este aumento das vantagens de classe. Uma hipótese bastante plausível é que haja estratificação social dentro dos sistemas educacionais, principalmente de ensino médio e superior. De fato, sabemos que este tipo de estratificação vem se ampliando bastante nas décadas de 1990 e 2000 (Mello, 2011). Tomando este fato como relevante podemos imaginar que as famílias em posições de classe mais vantajosas também são aquelas que garantem melhores instituições de ensino médio e superior para seus filhos. E que, embora estejamos observando uma tendência global de diminuição dos retornos educacionais, haveria de fato vantagens educacionais para pessoas que estudam em instituições de elite. Como nossos dados não diferenciam o tipo de instituição de ensino, observamos esse efeito no aumento do efeito direto das vantagens de classe (desigualdade de oportunidades) a partir de 1988 
para os homens e de 1996 para as mulheres. De qualquer forma, estes resultados indicam que, embora haja uma diminuição global da desigualdade de oportunidades, as vantagens de classe diretas, depois que controlamos por educação, estão aumentando e não diminuindo nas décadas de 1990 e 2000 no Brasil.

Finalmente, encontramos alguns indícios de uma diminuição das desigualdades de oportunidades educacionais entre 1996 e 2008. Estes indícios indicam que as políticas de expansão educacional avançadas durante os governos de FHC e Lula parecem estar contribuindo para diminuir as vantagens de classe no acesso e progressão ao sistema educacional. Embora as evidências sejam fracas (os coeficientes e tendências não são fortes e por vezes têm pouca significância estatística), são relevantes do ponto de vista substantivo, uma vez que sabemos e observamos (ver Tabela 1) a enorme expansão educacional que ocorreu neste período.

Os resultados deste artigo ajudam a completar uma série de quatro décadas de informações sobre mobilidade social e desigualdade de oportunidades no Brasil. Os resultados são altamente relevantes e esperamos que incentivem novos estudos sobre estratificação e mobilidade social no Brasil. Ainda há muito para ser estudado e desvendado nesta área de importância crucial para a Sociologia brasileira.

(Recebido para publicação em janeiro de 2012)

(Reapresentado em maio de 2012)

(Aprovado para publicação em junho 2012) 


\section{NOTAS}

1. O coeficiente de Gini - que varia entre 0 para nenhuma desigualdade e 1 para desigualdade máxima - foi de 0,63 em 1989, 0,59 em 1995, e 0,54 em 2008.

2. Neste artigo analiso dados para adultos entre 30 e 64 anos de idade entre 1973 e 2008. Estas pessoas passaram pelo sistema educacional em diferentes épocas históricas, ao longo das quais houve grandes mudanças no sistema educacional. Por isso usarei ora os termos educação primária (8 primeiras séries) e secundária (3 séries), ora os termos educação fundamental (9 primeiras séries, incluindo a classe de alfabetização, que era excluída na classificação anterior) e média (3 anos). Na realidade há indivíduos que estiveram na escola quando o sistema ainda era dividido entre elementar (4 primeiros anos), médio (4 anos) e clássico ou científico ( 3 anos).

3. Para mais detalhes sobre os procedimentos amostrais da PDSD ver documentação na página do Centro para o Estudo da Riqueza e da Estratificação Social (CERES): http: / / ceres.iesp.uerj.br/.

4. Comparative Analysis of Social Mobility in Industrial Nations (CASMIN). Este esquema foi desenvolvido por diversos pesquisadores e é usado amplamente. Para uma referência mais usada veja Goldthorpe e Erickson (1993).

5. Para elaboração deste artigo fizemos diversas outras análises não apresentadas. Em particular analisamos mudanças ao longo de coortes de idade e comparamos estas mudanças com as mudanças ao longo dos cinco anos de pesquisa (período). Estas análises indicam que a mudanças na fluidez social ao longo do período, mas não das coortes de idade. Tais análises implicavam uma desagregação ainda maior do que a aqui apresentada.

6. Uma análise não apresentada usando 11 classes sociais (apenas para os 4 primeiros anos) chegou a conclusões semelhantes.

7. Por falta de espaço não incluímos estas tabelas no artigo, mas podemos disponibilizá-las caso algum pesquisador tenha interesse.

8. "Unidiff" é a abreviação usada por Goldthorpe e Erickson (1993) para o termo "uniform difference model".

9. Se tivéssemos apresentado o número para coortes de idade, teríamos observado uma diminuição ainda maior. 


\section{REFERÊNCIAS BIBLIOGRÁFICAS}

ALBANEZ, Alícia, FERREIRA, Francisco e FRANCO, Creso. (2002), "A Escola Importa?: Determinantes da Eficiência e Equidade no Ensino Fundamental Brasileiro". Pesquisa e Planejamento Econômico, vol. 23, no 3, pp. 453-476.

ALBERNAZ, Angela, FERREIRA, Francisco e FRANCO, Creso. (2002), "Qualidade e Equidade na Educação Fundamental Brasileira". Texto para Discussão, no 455. Departamento de Economia, PUC-Rio.

ALVEZ, Fátima Cristina de M. (2007), Qualidade na Educação Fundamental Pública nas Capitais Brasileiras: Tendências, Contextos e Desafios. Tese de Doutorado. Departamento de Educação, Pontifícia Universidade Católica do Rio de Janeiro. Rio de Janeiro, $243 p$.

BREEN, Richard. (2011), "Educational Expansion e Social Mobility in the 20th Century". Social Forces, vol. 89, no 2, pp. 365-388.

(2004), Social Mobility in Europe. Oxford, Oxford University Press.

e JONSSON Jan. (2007), "Explaining Change in Social Fluidity: Educational Equalization, and Educational Expansion in Twentieth-Century Sweden". American Journal of Sociology, vol. 112, no 6, pp. 1775-1810.

FERNANDES, Danielle C. (2001), Raça, Origem Socioeconomica e Desigualdade Educacional no Brasil: Uma Análise Longitudinal. Trabalho apresentado no XXV Encontro Anual da Anpocs, Caxambu, MG, de 16-20 de outubro.

FERREIRA, Francisco, LEITE, Phillippe, LICHFIELD, Julie A. e ULYSSEA, Gabriel. (2006), "Ascensão e Queda da Desigualdade de Renda no Brasil". Econômica, vol. 8, no 1, pp. 147-169.

FRANCO, Creso, ALVES, Fatima e BONAMINO, Alicia. (2007), "Quality of Education in Brazil: Policies, Potentialities and Limits". Educação e Sociedade, vol. 28, no 100, pp. 989-1014.

GOLDTHORPE, John H. (1983), "Women e Class Analysis: In Defense of the Conventional View". Sociology, no 7, pp. 465-488.

. (2000), On Sociology: Numbers, Narratives and the Integration of Research and Theory. Oxford, Oxford University Press.

e ERICKSON, Robert. (1993), The Constant Flux: A Study of Class Mobility in Industrial Societies. Oxford, Oxford University Press.

HASENBALG, Carlos Alfredo e SILVA, Nelson do Valle (2003), Origens e Destinos: Desigualdades Sociais ao Longo da Vida. Rio de Janeiro, Topbooks.

. (1999), "Race, Schooling and Social Mobility in Brazil". Ciência e Cultura: Journal of the Brazilian Association for the Advancement of Science, no 51, pp. 457-463.

(1988), Estrutura Social, Mobilidade e Raça. Rio de Janeiro, IUPERJ/Vértice.

HOUT, Michael. (1988), "More Universalism, Less Structural Mobility: The American Occupational Structure in the 1980's". American Journal of Sociology, no 93, pp. 1358-1400. 
ISHIDA, Hiroshi. (2005), Social Stratification and Social Mobility in Late-Industrializing Countries. Tokyo, University of Tokyo.

MELLO, Jorge Cássio R. S. (2011), Área de Formação e Diferenciação Institucional: Evidências de Estratificação dos Estudantes no Ensino Superior Brasileiro. Tese de Doutorado. Programa de Pós-graduação em Educação, PUC-RIO. Rio de Janeiro.

PASTORE, José. (1981), Inequality and Social Mobility in Brazil. Madison, University of Wisconsin Press. e SILVA, Nelson do Valle. (2000), Mobilidade Social no Brasil. São Paulo, Markon.

POWERS, Daniel e XIE, Yu. (2000), Statistical Methods for Categorical Data Analysis. New York, Academic Press.

RAFTERY, Adrian. (1986), "Choosing Models for Cross-Classification". American Sociological Review, vol. 51, no 1, pp. 145-146.

. (1995), Bayesian Model Selection in Social Research. Sociological Methodology, vol. 25, pp. 111-196.

RIBEIRO, Carlos Antonio Costa. (2006), "Raça, Classe e Mobilidade Social no Brasil". DADOS, vol. 49, no 4, pp. 833-873.

. (2007), Estrutura de Classe e Mobilidade Social no Brasil. Bauru, SP, EDUSC.

(2009), Desigualdade de Oportunidades no Brasil. Belo Horizonte, Argvmentvm.

. (2011), "Desigualdade de Oportunidades e Resultados Educacionais no Brasil". DADOS, vol. 54, no 1, pp. 41-88.

e SCALON, Maria Celi. (2001), "Mobilidade de Classes no Brasil em Perspectiva Comparada". DADOS, vol. 44, no 1, pp. 53-96.

SCALON, Maria Celi. (1999), Mobilidade Social no Brasil: Padrões e Tendências. Rio de Janeiro, Revan/IUPERJ-UCAM.

SILVA, Nelson do Valle. (1979), "As Duas Faces da Mobilidade". DADOS, no21, pp. 49-67. . (1999), "Mobilidade Social", in S. Miceli (org.), Sociologia 2: O que Ler na Ciência Social Brasileira (1970-1995). São Paulo, Editora Sumaré.

e RODITI, Déborah. (1986), "Et plus ça Change... Tendências Históricas de Fluidez Social no Brasil". DADOS, vol. 29, no 3, pp. 345-363.

TORCHE, Florencia e RIBEIRO, Carlos Antonio Costa. (2010), "Pathways of Change in Social Mobility: Industrialization, Education and Growing Fluidity in Brazil". Research in Social Stratification and Mobility, vol. 28, no 3, pp. 291-307.

WEAKLIEM, David. (1999), "A Critique of the Bayesian Information Criterion for Model Selection". Sociological Methods e Research, no 27, pp. 359-397.

XIE, Yu. (1992), "The Long-Multiplicative Layer Effect Model for Comparing Mobility Tables". American Sociological Review, no 16, pp. 159-183. 


\author{
ABSTRACT \\ Four Decades of Social Mobility in Brazil
}

This article analyzes intergenerational class mobility and inequality of opportunities over the last 40 years in Brazil. We draw on five national sample surveys conducted from 1973 to 2008 in order to examine the mechanisms that led to changes in social fluidity (inequality of opportunities) for men and women. The analyses show that there was a substantial decrease in inequality of opportunities (increase in social fluidity). The decrease in inequality of opportunities in Brazil relates to two mechanisms: a reduction in educational returns during this period, and a decrease in the direct effect of class of origin on class destination, discounting the effect of educational attainment, until 1988 for men and until 1996 for women. Beginning in these two years, we detect an increase in the direct effect of class of origin on class destination, controlling for education. We also discuss the principal consequences of the study's findings for the analysis of social inequalities in Brazil.

Key words: social mobility; inequality of opportunities; education

\title{
RÉSUMÉ
}

\section{Quatre Décenies de Mobilité Sociale au Brésil}

Dans cet article, on examine la mobilité de classe intergénérationnelle et l'inégalité des chances au long des 40 dernières années au Brésil. On s'est servi de cinq recherches nationales par échantillon effectuées entre 1973 et 2008 afin d'examiner les mécanismes qui ont provoqué des changements de fluidité sociale (inégalité des chances) pour les hommes et les femmes. Ces analyses révèlent une forte diminution de l'inégalité des chances (augmentation de la fluidité sociale). Cette diminution de l'inégalité des chances au Brésil est liée à deux mécanismes: la reduction des correlation entre éducation et classes de destination tout au long de cette période, ainsi que la diminution de l'effet direct des classes d'origine sur celles de destination, sans tenir compte de l'effet de l'éducation obtenue, jusqu'en 1988 pour les hommes et jusqu'en 1996 pour les femmes. À partir de ces deux dates, on vérifie une augmentation de l'effet direct de la classe d'origine sur la classe de destination, selon un contrôle par l'éducation. Les principales conséquences des résultats obtenus pour l'analyse des inégalités sociales au Brasil, sont aussi étudiées.

Mots-clés: mobilité sociale; inégalité des chances; éducation 